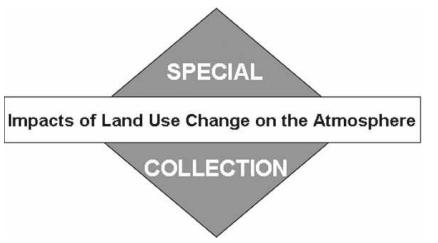

\title{
An Urban Parameterization for a Global Climate Model. Part I: Formulation and Evaluation for Two Cities
}

\author{
K. W. Oleson and G. B. Bonan \\ Climate and Global Dynamics Division, National Center for Atmospheric Research, ${ }^{*}$ Boulder, Colorado \\ J. FEDDEMA \\ Department of Geography, University of Kansas, Lawrence, Kansas \\ M. VERTENSTEIN \\ Climate and Global Dynamics Division, National Center for Atmospheric Research, * Boulder, Colorado \\ C. S. B. GRIMMOND \\ Department of Geography, King's College, London, United Kingdom
}

(Manuscript received 26 September 2006, in final form 31 July 2007)

\begin{abstract}
Urbanization, the expansion of built-up areas, is an important yet less-studied aspect of land use/land cover change in climate science. To date, most global climate models used to evaluate effects of land use/land cover change on climate do not include an urban parameterization. Here, the authors describe the formulation and evaluation of a parameterization of urban areas that is incorporated into the Community Land Model, the land surface component of the Community Climate System Model. The model is designed to be simple enough to be compatible with structural and computational constraints of a land surface model coupled to a global climate model yet complex enough to explore physically based processes known to be important in determining urban climatology. The city representation is based upon the "urban canyon" concept, which consists of roofs, sunlit and shaded walls, and canyon floor. The canyon floor is divided into pervious (e.g., residential lawns, parks) and impervious (e.g., roads, parking lots, sidewalks) fractions. Trapping of longwave radiation by canyon surfaces and solar radiation absorption and reflection is determined by accounting for multiple reflections. Separate energy balances and surface temperatures are determined for each canyon facet. A one-dimensional heat conduction equation is solved numerically for a 10-layer column to determine conduction fluxes into and out of canyon surfaces. Model performance is evaluated against measured fluxes and temperatures from two urban sites. Results indicate the model does a reasonable job of simulating the energy balance of cities.
\end{abstract}

\section{Introduction}

Land use/land cover change is increasingly being recognized as an important yet poorly quantified component of global climate change (Houghton et al. 2001). Land use/land cover change mechanisms include both transformation of natural land surfaces to those serving

* The National Center for Atmospheric Research is sponsored by the National Science Foundation.

Corresponding author address: Keith Oleson, National Center for Atmospheric Research, P.O. Box 3000, Boulder, CO 803073000.

E-mail: oleson@ucar.edu human needs (i.e., direct anthropogenic change; e.g., conversion of tropical forest to agriculture) as well as changes in land cover on longer time scales that are due to biogeophysical feedbacks between atmosphere and land (i.e., indirect change; Cramer et al. 2001; Foley et al. 2005). Global and regional models have been used extensively to investigate effects of direct and indirect land use/land cover change mechanisms on climate (Copeland et al. 1996; Betts 2001; Eastman et al. 2001; Pielke et al. 2002; Feddema et al. 2005). However, all of these studies have focused on land use/land cover related to changes in vegetation types. Urbanization, or the expansion of built-up areas, is an important yet less studied aspect of anthropogenic land use/land cover change in climate science. 
Although currently only about $1 \%-3 \%$ of the global land surface is urbanized, the spatial extent and intensity of urban development are expected to increase dramatically in the future (Shepherd 2005). More than one-half of the world's population currently lives in urban areas, and in Europe, North America, and Japan at least $80 \%$ of the population resides in urban areas (Elvidge et al. 2004). Policymakers and the public are most interested in the effects of climate change on people where they live. Because urban and nonurban areas may have different sensitivities to climate change, it is possible that the true climate change signal within urban areas may only be estimated if urban areas are explicitly modeled in climate change simulations (Best 2006).

Numerical modeling of the urban energy balance was first attempted nearly 40 years ago [see Brown (2000) for a comprehensive historical overview of modeling efforts]. However, until recently, most modern land surface models (i.e., second- or third-generation models; Sellers et al. 1997) have not formally included urban parameterizations. Masson (2006) classifies urban parameterizations in three general categories: 1) empirical models; 2) vegetation models, with and without drag terms, adapted to include an urban canopy; and 3) single-layer and multilayer models that include a threedimensional representation of the urban canopy. Empirical models (e.g., Oke and Cleugh 1987) rely on statistical relations determined from observed data. As such, they are generally limited to the range of conditions experienced during the observation campaign. Vegetation models adapted for the urban canopy generally focus on modifying important surface parameters to better represent urban surfaces [e.g., surface albedo, roughness length, displacement height, surface emissivity, heat capacity, and thermal conductivity (e.g., Taha 1999)].

These relatively simple approaches (i.e., categories 1 and 2 above) may arguably be justified based on the fact that detail in complex models may be lost when averaged to a coarse grid (Taha 1999). However, they may not have sufficient functionality to be suitable for inclusion in global climate models and may require global derivation of parameters that are difficult to interpret physically [e.g., the surface type-dependent empirical coefficients for storage heat flux in the Objective Hysteresis Model (Grimmond et al. 1991)]. Furthermore, such approaches may not fully describe the fundamental processes that determine urban effects on climate (Piringer et al. 2002). On the other hand, the level of complexity in a model is limited by the availability of the data that the model requires, the computational burden imposed, and difficulty in understanding com- plex behavior of the model. Here, following recent developments in detailed urban parameterizations designed for mesoscale models (Masson 2000; Grimmond and Oke 2002; Martilli et al. 2002), we describe a singlelayer urban canopy model that is simple enough to be compatible with structural, computational, and data constraints of a land surface model coupled to a global climate model yet is complex enough to enable exploration of physically based processes known to be important in determining urban climatology. Several of the parameterizations are based on the Town Energy Balance (TEB) Model (Masson 2000; Masson et al. 2002, hereinafter MG02; Lemonsu et al. 2004). The urban model is implemented within version 3 of the Community Land Model (CLM3; Dickinson et al. 2006), which is the land surface component of the Community Climate System Model (CCSM; Collins et al. 2006). The model is evaluated by comparing simulated fluxes and surface temperatures with those observed at two urban sites.

\section{Model description}

\section{a. Atmospheric model coupling requirements}

The atmospheric model within CCSM requires fluxes of sensible and latent heat and momentum between the surface and lowest atmospheric model level as well as emitted longwave and reflected shortwave radiation (Fig. 1). These must be provided at a time step that resolves the diurnal cycle. Over other land surfaces, they are determined by current parameterizations in CLM3 (Oleson et al. 2004). An objective of this paper is to describe a set of parameterizations that determines the fluxes from an urban surface. The vertical spatial domain of the urban model extends from the top of the urban canopy layer (UCL) down to the depth of zero vertical heat flux in the ground (Oke 1987). The current state of the atmosphere (wind, temperature, and humidity) and downwelling fluxes (longwave and shortwave radiation and precipitation) at a given time step is used to force the urban model. The urban model then provides fluxes that are area averaged with other land cover (e.g., forests or cropland) if present within the model grid cell. The area-averaged fluxes are used as lower boundary conditions by the atmospheric model at the next time step.

\section{b. Structure}

Land surface heterogeneity in CLM3 is represented as a nested subgrid hierarchy in which grid cells are composed of multiple land units, snow/soil columns, and plant functional types. The first subgrid level, the 


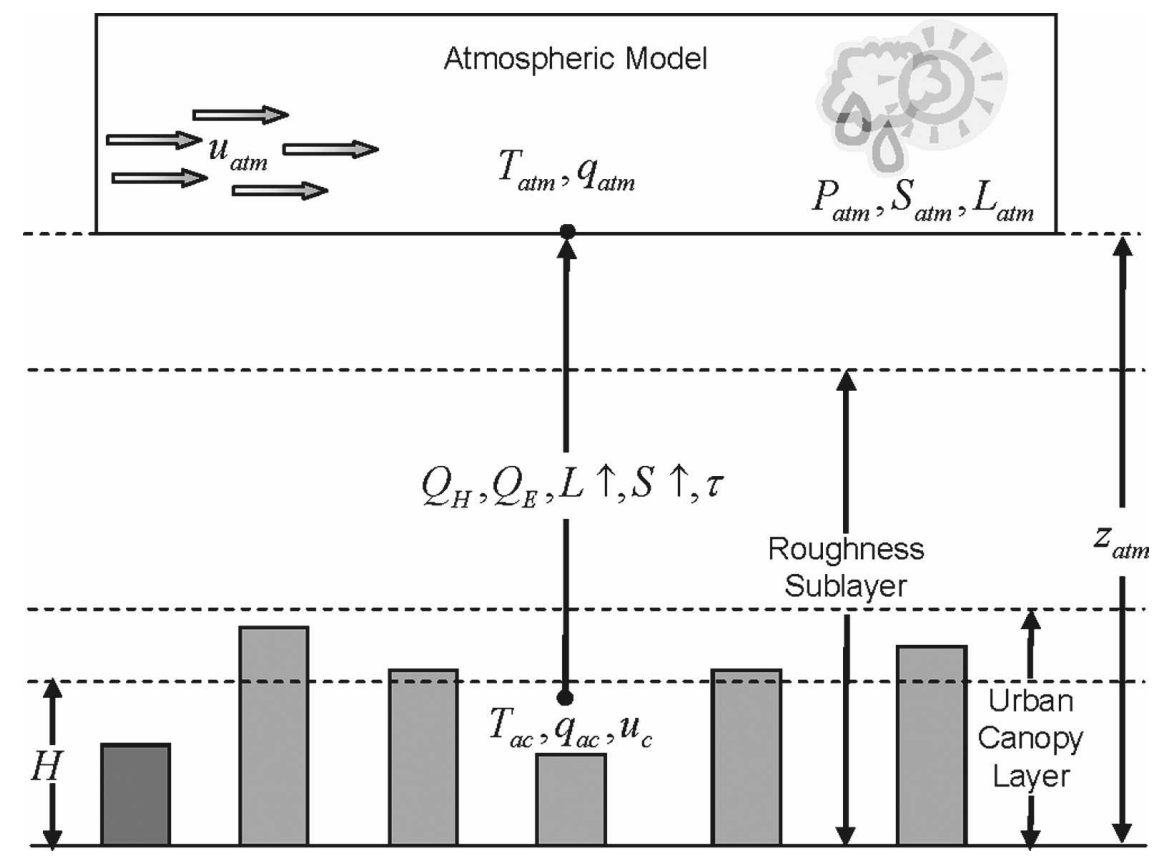

FIG. 1. Schematic of urban and atmospheric model coupling. The urban model is forced by the atmospheric model wind $u_{\text {atm }}$, temperature $T_{\text {atm }}$, specific humidity $q_{\text {atm }}$, precipitation $P_{\text {atm }}$, solar radiation $S_{\mathrm{atm}}$, and longwave radiation $L_{\mathrm{atm}}$ at reference height $z_{\mathrm{atm}}$. Fluxes from the urban land unit to the atmospheric model are turbulent sensible heat $Q_{H}$ and latent heat $Q_{E}$, momentum $\tau$, emitted longwave radiation $L \uparrow$ and reflected shortwave radiation $S \uparrow$. Air temperature $T_{\text {ac }}$, specific humidity $q_{\text {ac }}$, and wind speed $u_{c}$ within the urban canopy layer are diagnosed by the urban model. Here $H$ is the average building height.

land unit, is intended to capture the broadest spatial patterns of subgrid heterogeneity. The model described here is designed to represent urban land units. The representation of the urban land unit is based on the canyon concept of Oke (1987). In this approach, the considerable complexity of the urban surface is reduced to a single urban canyon, here assumed to be of infinite length, consisting of a canyon floor of width $W$ bordered by two facing buildings of height $H$ (Fig. 2). Although the canyon floor is intended to represent various surfaces such as roads, parking lots, sidewalks, and residential lawns, for convenience we henceforth refer to the canyon floor as a road. The urban canyon consists of roof, sunlit and shaded wall, and pervious and impervious road, which are treated by the second subgrid level as "columns" within the land unit. The impervious road is intended to represent surfaces that are impervious to water infiltration (e.g., roads, parking lots, sidewalks) while the pervious road is intended to represent surfaces such as residential lawns and parks that may have active biophysical hydrology.

Biogeophysical processes are simulated for each of the five urban columns, and each column maintains its own prognostic variables (e.g., surface temperature; Fig. 2). The processes simulated include 1) absorption and reflection of solar radiation; 2) absorption, reflection, and emission of longwave radiation; 3) momentum, storage, turbulent sensible heat, and latent heat fluxes; 4) anthropogenic heat fluxes due to traffic and waste heat from building heating/air-conditioning; 5) heat transfer in roofs, building walls, and road including phase change; and 6) hydrology [roofs: storage of liquid and solid precipitation (ponding and dew), evaporation, surface runoff; walls: hydrologically inactive; impervious road: storage of liquid and solid precipitation (ponding and dew), evaporation, surface runoff; pervious road: evaporation, infiltration, surface runoff, subsurface drainage, redistribution of water within the column]. The heat and moisture fluxes from each surface interact with each other through a bulk air mass that represents air in the UCL for which specific humidity and temperature are predicted (section $2 \mathrm{~d}$ ). Note that here we model the UCL plus the air above the roofs (Fig. 1). This allows for mixing of above-roof air with canyon air.

An important design requirement of the model is that, where possible, consistency between urban and vegetation/soil model treatments of individual processes should be maintained. For example, the parameterization of heat conduction in soil surfaces should be 


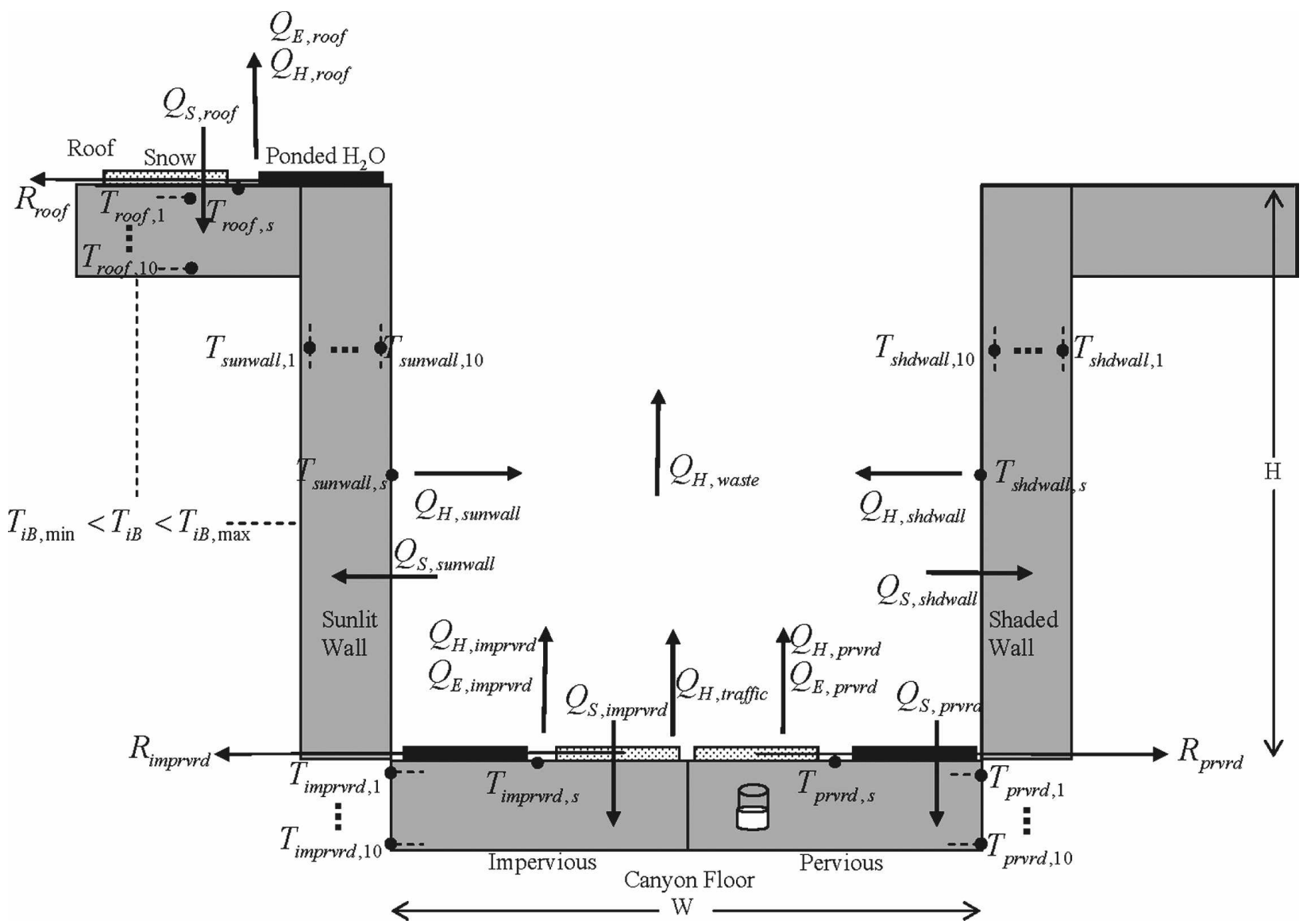

FIG. 2. Schematic overview of the modeled urban land unit. The canyon consists of roof, sunlit and shaded walls of height $H$, and a canyon floor of width $W$ divided into pervious and impervious fractions. For each of these surfaces, temperatures $T$ and sensible $\left(Q_{H}\right)$, latent $\left(Q_{E}\right)$, and storage $\left(Q_{S}\right)$ heat fluxes are simulated. Temperatures for each urban surface $u$ include surface temperature $T_{u, s}$ and internal temperatures for 10 layers $\left(T_{u, 1-10}\right)$. An internal building temperature $T_{\mathrm{iB}}$ is simulated that can be held at prescribed comfort levels $T_{\mathrm{iB}, \min }$ and $T_{\mathrm{iB}, \max }$, thereby simulating heating and/or air-conditioning. Hydrology on the roof and canyon floor is simulated; walls are hydrologically inactive. Snowpacks can form on the active surfaces. A certain amount of liquid water is allowed to pond on these surfaces, which supports evaporation. Snow meltwater or water in excess of the maximum ponding depth runs off ( $R_{\text {roof }}, R_{\text {imprvrd }}$, $\left.R_{\text {prvrd }}\right)$. The pervious canyon floor has a soil moisture store to support evaporation. Anthropogenic fluxes from traffic $\left(Q_{H, \text { traffic }}\right)$ or other sources such as heating and/or air-conditioning waste heat $\left(Q_{H \text {,waste }}\right)$ can be accommodated. Incident, reflected, and net solar and longwave radiation are calculated for each individual surface but for clarity are not shown.

transferable to individual urban surfaces (e.g., roofs) as long as the different thermal properties of urban surfaces are taken into account. In a similar way, snowpack formation and melt should be fundamentally the same. Thus, we use the well-established and validated CLM3 parameterizations for these processes as described below.

\section{c. Radiative fluxes}

\section{1) Roof AND ROAD ALBEDO}

The albedo of roof and road is a weighted combination of snow-free "ground" albedos and snow albedos:

$$
\alpha_{u, \Lambda}^{b}\left(1-f_{u, \text { sno }}\right)+\alpha_{\mathrm{sno}, \Lambda}^{b} f_{u, \text { sno }}
$$

where $u$ denotes roof or impervious or pervious road; $\Lambda$ denotes visible (VIS) or near-infrared (NIR) waveband; $b$ denotes direct beam ( $b=\operatorname{dir})$ or diffuse $(b=$ dif) albedos; and $f_{u \text {, sno }}$ is the fraction of surface covered with snow (Bonan 1996). The snow-free urban albedos $\alpha_{u, \Lambda}^{b}$ are input parameters. Snow albedos are set to $\alpha_{\mathrm{sno}, \mathrm{VIS}}^{b}=0.66$ and $\alpha_{\mathrm{sno}, \mathrm{NIR}}^{b}=0.56$, which fall about in the middle of the range given by Oke (1987).

\section{2) INCIDENT-DIRECT SOLAR RADIATION}

The direct beam solar radiation incident on the roof is simply the atmospheric solar radiation received on a horizontal surface:

$$
S_{\text {roof }} \downarrow_{\Lambda}^{\operatorname{dir}}=S_{\text {atm }} \downarrow_{\Lambda}^{\operatorname{dir}},
$$


where $S_{\text {atm }} \downarrow$ is atmospheric solar radiation provided by the atmospheric model at each time step. The direct beam solar radiation received by walls and road is adjusted for orientation and shadowing following the approach of Masson (2000). Depending on canyon orientation, one of the two walls in the canyon is fully or partially illuminated by solar radiation, the other is shaded. The shaded wall similarly casts a shadow onto the road. Radiative fluxes for the sunlit wall, shaded wall, and road derived for a canyon oriented perpendicular to the sun's direction are integrated over all canyon orientations to account for other canyon orientations. The direct beam solar radiation incident on walls and road is

$$
\begin{aligned}
S_{\text {shdwall }} \downarrow_{\Lambda}^{\text {dir }}= & 0, \\
S_{\text {sunwall }} \downarrow_{\Lambda}^{\text {dir }}= & 2 S_{\text {atm }} \downarrow_{\Lambda}^{\operatorname{dir}}\left[\frac{W}{H}\left(\frac{1}{2}-\frac{\theta_{0}}{\pi}\right)\right. \\
& \left.+\frac{1}{\pi} \tan \mu\left(1-\cos \theta_{0}\right)\right], \text { and } \\
S_{\text {imprvrd }} \downarrow_{\Lambda}^{\text {dir }}= & S_{\text {prvrd }} \downarrow_{\Lambda}^{\text {dir }} \\
= & S_{\text {atm }} \downarrow_{\Lambda}^{\operatorname{dir}}\left[\frac{2 \theta_{0}}{\pi}-\frac{2}{\pi} \frac{H}{W} \tan \mu\left(1-\cos \theta_{0}\right)\right] .
\end{aligned}
$$

Here, $\theta_{0}$ is the critical canyon orientation (the angle between sun direction and along-canyon axis) for which the road is no longer illuminated:

$$
\theta_{0}=\sin ^{-1}\left(\frac{W}{H \tan \mu}\right)
$$

where $\mu$ is solar zenith angle.

Our approach explicitly distinguishes between sunlit and shaded walls. We do so to better account for differences in surface temperature within the canyon. At any given time of day, some walls in a canyon are illuminated by sunlight and some are shaded. Our approach distinguishes between these two categories. We stress, however, that the sunlit and shaded walls are not meant to represent particular walls in the canyon but rather merely account for sunlit and shaded surface regardless of orientation.

\section{3) VIEW FACTORS}

The interaction of diffuse radiation (i.e., longwave and reflected solar radiation) between urban surfaces depends on angle (view) factors, that is, the fraction of diffusely distributed energy leaving one "surface" (e.g., sky) that arrives at another surface (e.g., wall; Sparrow and Cess 1978). The sky-wall and wall-sky view factors are

$$
\Psi_{\text {sky-wall }}=\Psi_{\text {wall-sky }}=\frac{\frac{1}{2}\left[\frac{H}{W}+1-\sqrt{1+\left(\frac{H}{W}\right)^{2}}\right]}{\frac{H}{W}} .
$$

In a similar way, the sky-road and road-sky view factors are

$$
\Psi_{\text {sky-road }}=\Psi_{\text {road-sky }}=\sqrt{1+\left(\frac{H}{W}\right)^{2}}-\frac{H}{W} .
$$

By symmetry,

$$
\Psi_{\text {wall-road }}=\Psi_{\text {wall-sky }},
$$

and the other view factors can be deduced from conservation of energy as

$$
\begin{aligned}
& \Psi_{\text {road-wall }}=0.5\left(1-\Psi_{\text {road-sky }}\right) \quad \text { and } \\
& \Psi_{\text {wall-wall }}=1-\Psi_{\text {wall-sky }}-\Psi_{\text {wall-road }} .
\end{aligned}
$$

The incident diffuse solar radiation on roof, walls, and road can be determined from view factors as

$$
\begin{aligned}
S_{\text {roof }} \downarrow_{\Lambda}^{\text {dif }} & =S_{\text {atm }} \downarrow_{\Lambda}^{\text {dif }}, \\
S_{\text {imprvrd }} \downarrow_{\Lambda}^{\text {dif }} & =S_{\text {prvrd }} \downarrow_{\Lambda}^{\text {dif }}=S_{\text {atm }} \downarrow_{\Lambda}^{\text {dif }} \Psi_{\text {sky-road }}, \quad \text { and } \\
S_{\text {shdwall }} \downarrow_{\Lambda}^{\text {dif }} & =S_{\text {sunwall }} \downarrow_{\Lambda}^{\text {dif }}=S_{\text {atm }} \downarrow_{\Lambda}^{\text {dif }} \Psi_{\text {sky-wall }},
\end{aligned}
$$

where $S_{\text {atm }} \downarrow_{\Lambda}^{\text {dif }}$ is incident diffuse solar radiation from the atmospheric model.

\section{4) Absorbed and ReFlected SOlar Radiation}

The direct beam or diffuse net (absorbed) and reflected solar radiation for the roof are

$$
\begin{aligned}
\vec{S}_{\text {roof, } \Lambda}^{b} & =S_{\text {roof }} \downarrow_{\Lambda}^{b}\left(1-\alpha_{\text {roof }, \Lambda}^{b}\right) \quad \text { and } \\
S_{\text {roof }} \uparrow_{\Lambda}^{b} & =S_{\text {roof }} \downarrow_{\Lambda}^{b}\left(\alpha_{\text {roof }, \Lambda}^{b}\right) .
\end{aligned}
$$

The net and reflected solar radiation for walls and road and reflected solar radiation to the sky are determined numerically by allowing for multiple reflections. The multiple reflections are accounted for in five steps:

1) Determine the initial absorption and reflection by each urban surface and distribute this radiation to sky, road, and walls according to view factors.

2) Determine the amount of radiation absorbed and reflected by each urban surface after the initial reflection. The solar radiation reflected from walls to road is projected to road area by multiplying by height-to-width ratio $H / W$, and the solar radiation reflected from road to walls is projected to wall area by dividing by $H / W$. 
3) The absorbed radiation for the $i$ th reflection is added to the total absorbed by each urban surface.

4) The reflected solar radiation for the $i$ th reflection is distributed to sky, road, and walls according to view factors.

5) The reflected solar radiation to the sky for the $i$ th reflection is added to the total reflected solar radiation.

Steps $2-5$ are repeated until a convergence criterion (absorbed per unit incoming solar radiation for a given reflection is less than $1 \times 10^{-5}$ ) is met to ensure radiation is conserved.

The total direct beam or diffuse solar radiation reflected by the urban canyon (walls and road) is

$$
\begin{aligned}
S_{\text {uc }} \uparrow_{\Lambda}^{b}= & S_{\text {imprvrd }} \uparrow_{\Lambda}^{b}\left(1-f_{\text {prvrd }}\right)+S_{\text {prvrd }} \uparrow_{\Lambda}^{b} f_{\text {prvrd }} \\
& +\left(S_{\text {sunwall }} \uparrow_{\Lambda}^{b}+S_{\text {shdwall }} \uparrow_{\Lambda}^{b}\right) H / W,
\end{aligned}
$$

where $S_{\text {imprvrd }} \uparrow_{\Lambda}^{b}, S_{\text {prvrd }} \uparrow_{\Lambda}^{b}, S_{\text {sunwall }} \uparrow_{\Lambda}^{b}$, and $S_{\text {shdwall }} \uparrow_{\Lambda}^{b}$ are the solar radiation reflected from each urban surface to the sky after the final reflection. The total absorbed solar radiation is

$$
\begin{aligned}
\vec{S}_{\mathrm{uc}, \Lambda}^{b}= & \vec{S}_{\text {imprvrd }, \Lambda}^{b}\left(1-f_{\text {prvrd }}\right)+\vec{S}_{\text {prvrd }, \Lambda}^{b} f_{\text {prvrd }} \\
& +\left(\vec{S}_{\text {sunwall }, \Lambda}^{b}+\vec{S}_{\text {shdwall }, \Lambda}^{b}\right) H / W,
\end{aligned}
$$

where $f_{\text {pryrd }}$ is the pervious road fraction and $\vec{S}_{\text {imprvrd, } \Lambda}^{b}$, $\vec{S}_{\text {prvrd, },}^{b}, \vec{S}_{\text {sunwall, },}^{b}$, and $\vec{S}_{\text {shdwall, }, \Lambda}^{b}$ are the solar radiation absorbed by each urban surface after the final reflection. The direct beam or diffuse urban canyon albedos are

$\alpha_{\mathrm{uc}, \Lambda}^{b}=\frac{S_{\mathrm{uc}} \uparrow_{\Lambda}^{b}}{S_{\text {road }} \downarrow_{\Lambda}^{b}+\left(S_{\text {sunwall }} \downarrow_{\Lambda}^{b}+S_{\text {shdwall }} \downarrow_{\Lambda}^{b}\right) H / W}$,

where $S_{\text {road }} \downarrow_{\Lambda}^{b}$ is a combination of the contributions of impervious and pervious road.

Figure 3 shows the solar radiation absorbed by urban surfaces for a range of $H / W$ and two solar zenith angles. At both solar zenith angles, the absorbed solar radiation for the road decreases rapidly with increasing $H / W$ as the buildings shade more of the road. The shaded wall absorbs less solar radiation than the sunlit wall because it receives only diffuse radiation from the sun and reflected radiation from walls and road. The sunlit wall absorbs more solar radiation at larger solar zenith angles for $H / W$ less than about 3 because the incidence angle of the radiation is closer to zero. The sum of absorbed solar radiation for road, sunlit wall, and shaded wall, after converting wall fluxes to per unit ground area, is the canyon absorbed solar radiation. The absorbed solar radiation for the canyon increases slowly with increasing $H / W$.

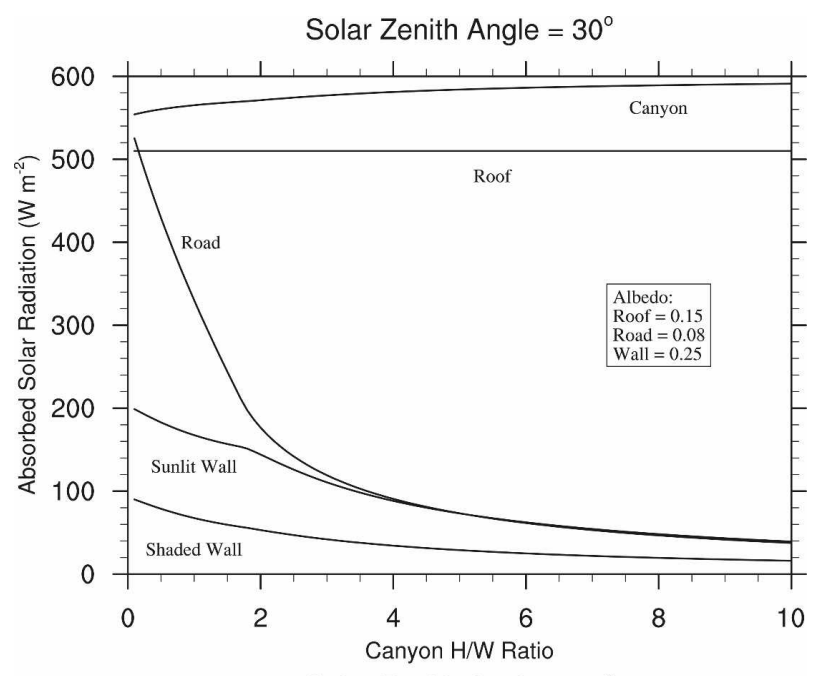

Solar Zenith Angle $=60^{\circ}$

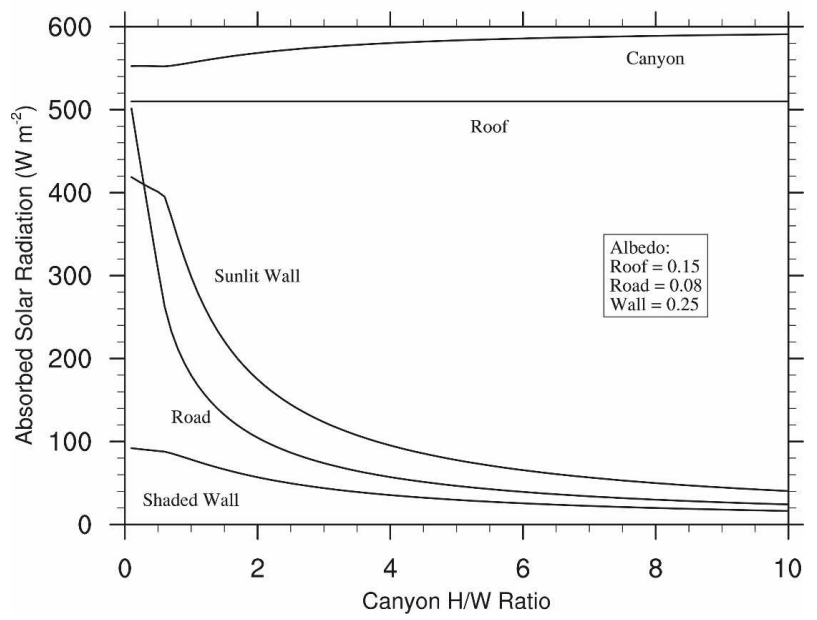

FIG. 3. Solar radiation absorbed by urban surfaces for solar zenith angles of (top) $30^{\circ}$ and (bottom) $60^{\circ}$ and height-to-width ratios of $0.1-10.0$. The atmospheric solar radiation is $S_{\text {atm }} \downarrow_{\Lambda}^{\text {dir }}=$ 400 and $S_{\text {atm }} \downarrow_{\Lambda}^{\text {dif }}=200 \mathrm{~W} \mathrm{~m}^{-2}$. Note that the sunlit and shaded wall fluxes are per unit wall area. The solar radiation absorbed by the canyon is the sum of road and wall fluxes after converting the wall fluxes to per unit ground area using the height-to-width ratio.

The canyon albedo (excluding the roof albedo) is shown in Fig. 4. We chose the same wall and road albedo used by Masson (2000) to evaluate the TEB canyon albedo. The canyon albedo shown in Fig. 4 has the same functional relationships with solar zenith angle and $H / W$ as TEB. In general, direct and diffuse canyon albedo decreases with increasing $H / W$ as more solar radiation is trapped and absorbed within the canyon. Trapping of solar radiation is less effective at larger solar zenith angles (sun closer to the horizon). At these large solar zenith angles and small $H / W$, the albedo increases because the higher albedo walls dominate the radiative exchange. 


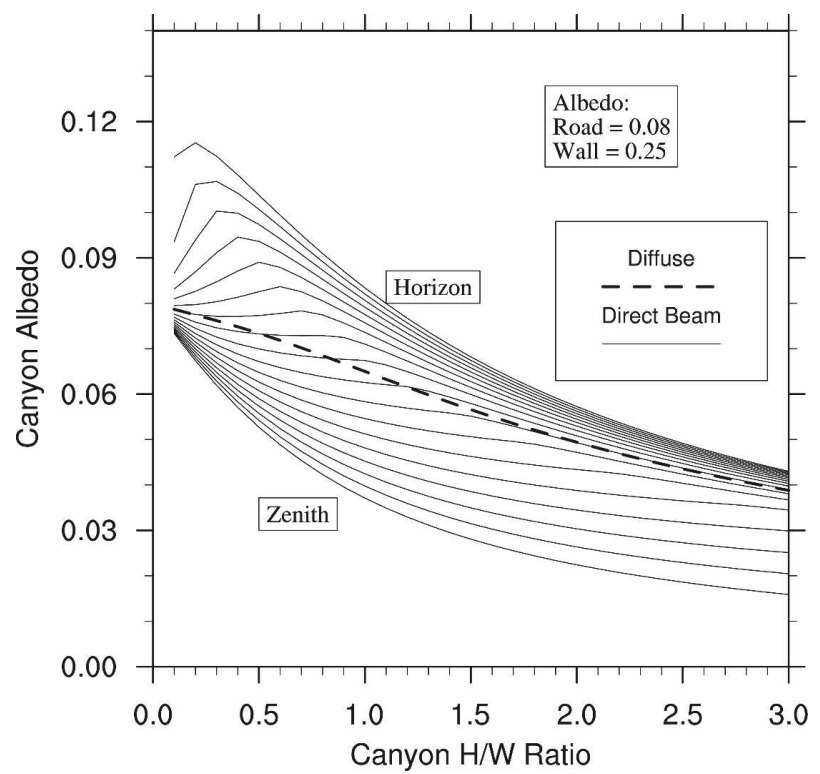

FIG. 4. Direct beam and diffuse albedo of the urban canyon (walls and road) as a function of height-to-width ratios from 0.1 to 3.0 in increments of 0.1 and solar zenith angles from $0^{\circ}$ to $85^{\circ}$ in increments of $5^{\circ}$. The atmospheric solar radiation is $S_{\mathrm{atm}} \downarrow_{\Lambda}^{\mathrm{dir}}=400$ and $S_{\text {atm }} \downarrow_{\Lambda}^{\text {dif }}=200 \mathrm{~W} \mathrm{~m}^{-2}$.

\section{5) LONGWAVE RADIATION}

Similar to incident diffuse solar radiation, the longwave radiation incident on walls and roads depends on view factors. The longwave radiation incident on roof, walls, and road is

$$
\begin{aligned}
L_{\text {roof }} \downarrow & =L_{\text {atm }} \downarrow, \\
L_{\text {imprvrd }} \downarrow & =L_{\text {prvrd }} \downarrow=L_{\text {atm }} \downarrow \Psi_{\text {sky-road }}, \quad \text { and } \\
L_{\text {shdwall }} \downarrow & =L_{\text {sunwall }} \downarrow=L_{\text {atm }} \downarrow \Psi_{\text {sky-wall }},
\end{aligned}
$$

where $L_{\text {atm }} \downarrow$ is longwave radiation from the atmosphere.

Emitted longwave radiation, a function of surface temperature and emissivity, must also be considered in addition to reflection and absorption when determining longwave interactions within the canyon. The net longwave radiation $\left(\mathrm{W} \mathrm{m}^{-2}\right)$ (positive toward the atmosphere) for the roof is

$$
\begin{aligned}
\vec{L}_{\text {roof }} & =L_{\text {roof }} \uparrow-L_{\text {atm }} \downarrow, \quad \text { where } \\
L_{\text {roof }} \uparrow & =\varepsilon_{\text {roof }} \sigma\left(T_{\text {roof }}\right)^{4}+\left(1-\varepsilon_{\text {roof }}\right) L_{\text {atm }} \downarrow
\end{aligned}
$$

is emitted plus reflected longwave radiation from the roof, $\varepsilon_{\text {roof }}$ is emissivity of the roof, $\sigma$ is the StefanBoltzmann constant $\left(\mathrm{W} \mathrm{m}^{-2} \mathrm{~K}^{-4}\right)$, and $T_{\text {roof }}$ is temperature of the roof (obtained from a numerical solution of the heat conduction equation as described in section 2e). Similar to albedo, the emissivity of each urban surface is a weighted combination of snow-free and snow emissivity:

$$
\varepsilon_{u}\left(1-f_{u, \text { sno }}\right)+\varepsilon_{\text {sno }} f_{u, \text { sno }},
$$

where $\varepsilon_{\text {sno }}=0.97$ (Oleson et al. 2004).

As with solar radiation, the longwave interactions within the urban canyon are determined numerically by allowing for multiple reflections until a convergence criterion is met (the absorbed longwave radiation for a given reflection is less than $1 \times 10^{-3}$ ). The first iteration includes emitted longwave from the urban surface. The net longwave radiation for the urban canyon (walls and road) is

$$
\begin{aligned}
\vec{L}_{\mathrm{uc}}= & \vec{L}_{\text {imprvrd }}\left(1-f_{\text {prvrd }}\right)+\vec{L}_{\text {prvrd }} f_{\text {prvrd }} \\
& +\left(\vec{L}_{\text {sunwall }}+\vec{L}_{\text {shdwall }}\right) H / W,
\end{aligned}
$$

where $\vec{L}_{\text {imprvrd }}, \vec{L}_{\text {prvrd }}, \vec{L}_{\text {sunwall }}$, and $\vec{L}_{\text {shdwall }}$ are net longwave radiation absorbed by each urban surface after the final reflection. The total reflected plus emitted longwave radiation is

$$
\begin{aligned}
L_{\mathrm{uc}} \uparrow= & L_{\text {imprvrd }} \uparrow\left(1-f_{\text {prvrd }}\right)+L_{\text {prvrd }} \uparrow f_{\text {prvrd }} \\
& +\left(L_{\text {sunwall }} \uparrow+L_{\text {shdwall }} \uparrow\right) H / W,
\end{aligned}
$$

where $L_{\text {imprvrd }} \uparrow, L_{\text {prvrd }} \uparrow, L_{\text {sunwall }} \uparrow$, and $L_{\text {shdwall }} \uparrow$ are longwave radiation reflected plus emitted from each urban surface to the sky after the final reflection.

Figure 5 shows the net longwave radiation for urban surfaces for two different emissivity configurations. The roof net longwave radiation is independent of $H / W$ and increases with higher emissivity. The net longwave radiation for road and walls decreases rapidly with increasing $H / W$ as more longwave radiation is trapped within the canyon. The walls have lower net longwave radiation than the road because their sky view factors are smaller. The net longwave radiation for the canyon increases slowly with increasing $H / W$ because of the larger surface area of walls.

\section{d. Turbulent, storage, and anthropogenic heat fluxes}

The net radiation for each urban surface $(\vec{S}-\vec{L})$ must be balanced by the sum of the turbulent and storage heat fluxes as

$$
\vec{S}-\vec{L}=Q_{H}+Q_{E}+Q_{S},
$$

where $Q_{H}$ is turbulent sensible heat flux $\left(\mathrm{W} \mathrm{m}^{-2}\right), Q_{E}$ is latent heat flux $\left(\mathrm{W} \mathrm{m}^{-2}\right)$, and $Q_{S}$ is net storage heat flux $\left(\mathrm{W} \mathrm{m}^{-2}\right)$. The individual urban surfaces have unique radiative, thermal, and hydrologic properties and environments. Thus, their sensible and latent heat fluxes are likely to be very different from each other. For example, the pervious road may have significant latent heat flux in comparison with the walls, which are assumed to be hydrologically inactive. Thus, fluxes 

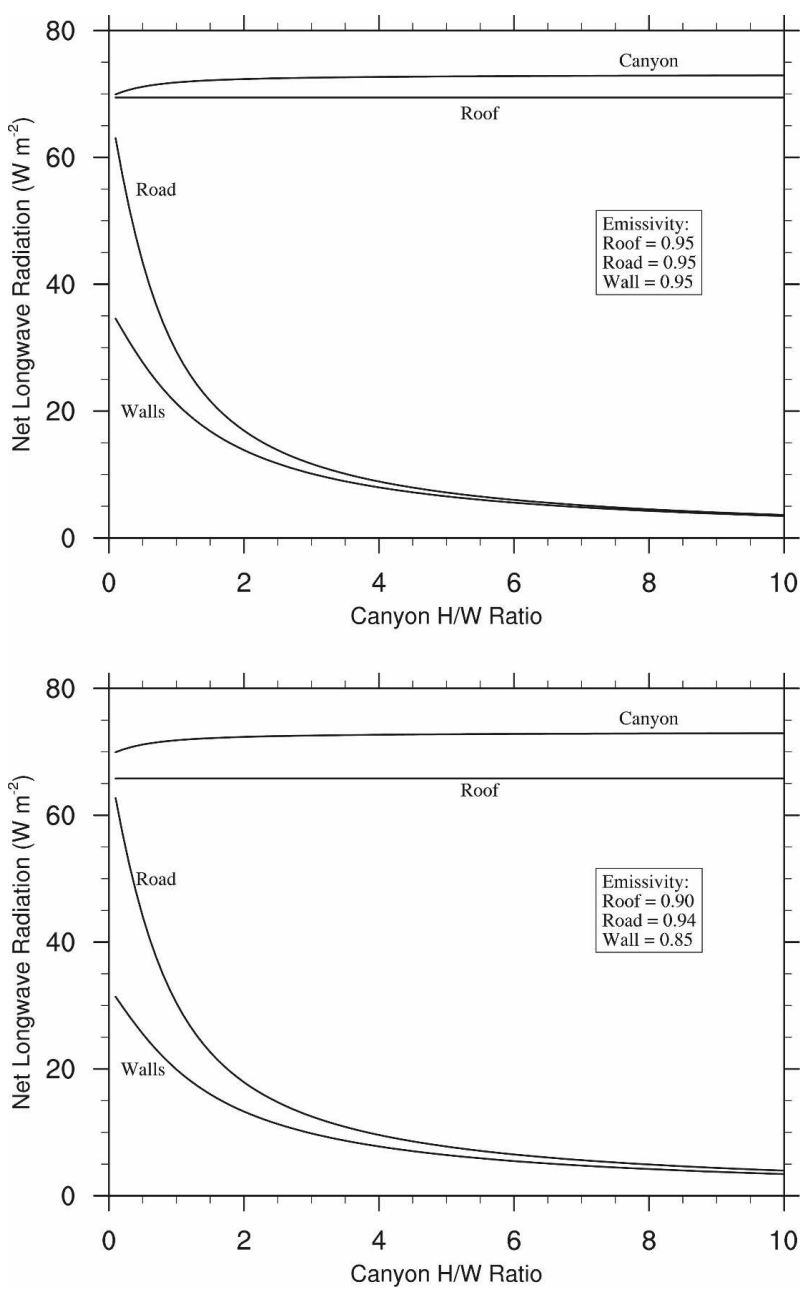

FIG. 5. Net longwave radiation (positive to the atmosphere) for urban surfaces for two different emissivity configurations and height-to-width ratios of 0.1-10.0. The atmospheric longwave radiation is $L_{\text {atm }} \downarrow=340 \mathrm{~W} \mathrm{~m}^{-2}$, and the temperature of each surface (including both walls) was prescribed as $292.16 \mathrm{~K}$. Note that the wall fluxes are per unit wall area. The net longwave radiation for the canyon is the sum of road and wall fluxes after converting the wall fluxes to per unit ground area using the height-to-width ratio.

from individual urban surfaces must be modeled separately. However, CLM3 directly interacts with the atmospheric model at only the lowest atmospheric layer, which is well above the roof level of the urban model at the horizontal scales to be modeled. As a consequence, fluxes from individual urban surfaces must be combined to obtain the total turbulent sensible and latent heat fluxes to be provided to the atmospheric model. Allowing urban surface fluxes to interact with each other through a bulk urban air mass is an acceptable approach analogous to the simulation of vegetated canopy fluxes (Fig. 1). This also allows for the solution of UCL air temperature and humidity, which are of interest to many applications. The approach shown in Fig. 1 is slightly different from that of Masson (2000) in that here, fluxes from the roof interact directly with the UCL air whereas in Masson (2000) the roof and urban canyon are modeled as two independent sources of heat and moisture fluxes to the atmosphere. Here, we assume that the actual roofs are at various heights in the urban canopy and hence interact directly with the wellmixed UCL air. The turbulent fluxes from the UCL to the atmosphere are derived from Monin-Obukhov similarity theory. The CLM3 formulations are used (Oleson et al. 2004) but are modified where appropriate for urban surfaces.

The flux formulations require estimates of roughness length and displacement height. We use the approach of Macdonald et al. (1998) to calculate displacement height $d_{\text {canopy }}$ and momentum roughness length $z_{0 m \text {,canopy }}$ for the urban canopy, which appears to be a reasonable compromise between minimizing input requirements and yielding acceptable results (Grimmond and Oke 1999a). The canopy displacement height $d_{\text {canopy }}(\mathrm{m})$ is

$$
d_{\text {canopy }}=H\left[1+\alpha^{-\lambda}\left(\lambda_{P}-1\right)\right],
$$

where $H$ is canyon (roof) height $(\mathrm{m}), \alpha=4.43$ is an empirical coefficient, and $\lambda_{p}$ is plan area index. The plan area index $\lambda_{p}$ is

$$
\lambda_{p}=\frac{H / W}{H / W+1} .
$$

The canopy roughness length $z_{0 m \text {,canopy }}(\mathrm{m})$ for momentum is

$$
\begin{aligned}
z_{0 m, \text { canopy }}= & H\left(1-\frac{d_{\text {canopy }}}{H}\right) \\
& \times \exp \left\{-\left[0.5 B \frac{C_{D}}{k^{2}}\left(1-\frac{d_{\text {canopy }}}{H}\right) \lambda_{F}\right]^{-0.5}\right\}
\end{aligned}
$$

where $B=1$ is a correction to the drag coefficient to account for variable obstacle shapes and flow conditions, $C_{D}=1.2$ is the depth-integrated mean drag coefficient for surface-mounted cubes in a shear flow, $k$ is the von Kármán constant, and $\lambda_{F}$ is frontal area index. The frontal area index $\lambda_{F}$ is

$$
\lambda_{F}=\left(1-\lambda_{P}\right)(H / W) \sqrt{\frac{B_{L} \lambda_{P}}{B_{S}}},
$$

where $B_{S} / B_{L}$ is the building shortside-to-longside ratio (here set equal to $\lambda_{p}$ ).

Following Masson (2000) and Lemonsu et al. (2004), wind speed in the canyon is the combination of the mean horizontal canyon wind $U_{\text {can }}\left(\mathrm{m} \mathrm{s}^{-1}\right)$ and turbulent (vertical) wind $W_{\text {can }}\left(\mathrm{m} \mathrm{s}^{-1}\right)$ : 


$$
U_{c}=\sqrt{U_{\mathrm{can}}^{2}+W_{\mathrm{can}}^{2}} .
$$

To calculate $U_{\text {can }}$, the wind speed at the top of the canyon is derived by assuming a logarithmic wind profile from the atmospheric reference height to the canyon top. The wind is then extrapolated to a height inside the canyon $(H / 2)$ using an exponential profile. For skimming flow $\left(H / W \geq 1\right.$; Oke 1987), a zero $U_{\text {can }}$ is assumed when the mean flow is perpendicular to the canyon orientation. After integration over $360^{\circ}$ (to account for all street orientations),

$$
\begin{aligned}
U_{\text {can }}= & V_{r} \frac{2}{\pi} \frac{\ln \left(\frac{H-d_{\text {canopy }}}{z_{\text {0m,canopy }}}\right)}{\ln \left(\frac{z_{\text {atm }, m}-d_{\text {canopy }}}{z_{0 m, \text { canopy }}}\right)} \\
& \times \exp \left[-0.5(H / W)\left(1-\frac{H_{w}}{H}\right)\right],
\end{aligned}
$$

where $H_{w}$ is the height at which the wind speed is estimated and $z_{\text {atm }, m}$ is the atmospheric forcing height for wind. For isolated roughness flow $(H / W<0.5)$, wind speed in the canyon is assumed to be independent of the orientation of the mean atmospheric flow above the canyon level:

$$
\begin{aligned}
U_{\text {can }}= & V_{r} \frac{\ln \left(\frac{H-d_{\text {canopy }}}{z_{\text {0m,canopy }}}\right)}{\ln \left(\frac{z_{\text {atm }, m}-d_{\text {canopy }}}{z_{0 m, \text { canopy }}}\right)} \\
& \times \exp \left[-0.5(H / W)\left(1-\frac{H_{w}}{H}\right)\right] .
\end{aligned}
$$

For wake interference flow $(0.5 \leq H / W<1.0)$,

$$
\begin{aligned}
U_{\text {can }}= & V_{r}\left[1+2\left(\frac{2}{\pi}-1\right)\left(\frac{H}{W}-\frac{1}{2}\right)\right] \frac{\ln \left(\frac{H-d_{\text {canopy }}}{z_{0 m, \text { canopy }}}\right)}{\ln \left(\frac{z_{\text {atm }, m}-d_{\text {canopy }}}{z_{0 m, \text { canopy }}}\right)} \\
& \times \exp \left[-0.5(H / W)\left(1-\frac{H_{w}}{H}\right)\right] .
\end{aligned}
$$

The magnitude of the reference level atmospheric wind is

$$
V_{r}=\sqrt{u_{\mathrm{atm}}^{2}+v_{\mathrm{atm}}^{2}},
$$

where zonal and meridional winds $u_{\text {atm }}$ and $v_{\text {atm }}\left(\mathrm{m} \mathrm{s}^{-1}\right)$ are at height $z_{\text {atm }, m}$. The turbulent (vertical) wind $W_{\text {can }}$ $\left(\mathrm{m} \mathrm{s}^{-1}\right)$ is assumed to be equal to the friction velocity (Masson 2000), which is determined from the solution for turbulent fluxes.

The sensible heat fluxes from each urban surface to the UCL air and from UCL air to the atmosphere are

$$
\begin{aligned}
Q_{H, u}= & -\rho_{\mathrm{atm}} C_{p} \frac{T_{\mathrm{ac}}-T_{g, u}}{r_{s, u}} \text { and } \\
Q_{H}= & -\rho_{\mathrm{atm}} C_{p} \frac{\theta_{\mathrm{atm}}-T_{\mathrm{ac}}}{r_{\mathrm{ah}}}=W_{\text {roof }} Q_{H, \text { roof }}+\left(1-W_{\mathrm{roof}}\right) \\
& \times\left[f_{\mathrm{prvrd}} Q_{H, \mathrm{prvrd}}+\left(1-f_{\text {prvrd }}\right) Q_{H, \text { imprvrd }}+\frac{H}{W} Q_{H, \text { sunwall }}+\frac{H}{W} Q_{H, \text { shdwall }}\right]+Q_{H, \text { traffic }}+Q_{H, \text { wasteheat }},
\end{aligned}
$$

where $T_{g}$ is surface temperature and $T_{\mathrm{ac}}$ is air temperature in the UCL. The resistances to sensible heat and latent heat transfer between canyon surfaces and UCL air depend only on canyon wind speed, following Masson (2000). These surface resistances $\left(\mathrm{s} \mathrm{m}^{-1}\right)$ are determined from (Rowley et al. 1930)

$$
r_{s, u}=\frac{\rho_{\mathrm{atm}} C_{p}}{11.8+4.2 U_{c}} .
$$

The terms $Q_{H \text {,traffic }}$ and $Q_{H \text {,wasteheat }}$ are the anthropogenic sensible heat flux from traffic and from waste heat generated by domestic heating/cooling, respectively. An example of how these fluxes are parameterized can be found in a companion paper (Oleson et al. 2008, hereinafter Part II).

Equations (38) and (39) can be solved for $T_{\mathrm{ac}}$ as

$$
T_{\mathrm{ac}}=\frac{\left(\begin{array}{c}
c_{a}^{h} \theta_{\mathrm{atm}}+c_{\mathrm{roof}} T_{g, \text { roof }}+c_{\text {prvrd }} T_{g, \text { prvrd }}+c_{\text {imprvrd }} T_{g, \text { imprvrd }} \\
+c_{\text {sunwall }} T_{g, \text { sunwall }}+c_{\text {shdwall }} T_{g, \text { shdwall }}+\frac{Q_{H, \text { traffic }}}{\rho_{\text {atm }} C_{p}}+\frac{Q_{H, \text { wasteheat }}}{\rho_{\text {atm }} C_{p}}
\end{array}\right)}{c_{a}^{h}+c_{\text {roof }}+c_{\text {prvrd }}+c_{\text {imprvrd }}+c_{\text {sunwall }}+c_{\text {shdwall }}},
$$


where $c_{a}^{h}$ is the sensible heat conductance from the canopy air to the atmosphere $\left(1 / r_{\text {ah }}\right)$ and $c_{\text {roof }}, c_{\text {prvrd }}$, $c_{\text {imprrrd }}, c_{\text {sunwall }}$, and $c_{\text {shdwall }}$ are the weighted heat conductances from urban surfaces to canopy air.

In a similar way, the system of equations for the UCL air specific humidity $q_{\text {ac }}$ is

$$
\begin{aligned}
Q_{E, \text { roof }} & =-\rho_{\text {atm }} \lambda \frac{f_{\text {wet,roof }}\left(q_{\mathrm{ac}}-q_{g, \text { roof }}\right)}{r_{s, \text { roof }}}, \\
Q_{E, \text { prvrd }} & =-\rho_{\text {atm }} \lambda \frac{q_{\mathrm{ac}}-q_{g, \text { prvrd }}}{r_{s, \text { prvrd }}},
\end{aligned}
$$

$Q_{E, \text { imprvrd }}=-\rho_{\text {atm }} \lambda \frac{f_{\text {wet,imprvrd }}\left(q_{\mathrm{ac}}-q_{g, \text { imprvrd }}\right)}{r_{s, \text { imprvrd }}}$, and

$$
\begin{aligned}
Q_{E}= & -\rho_{\mathrm{atm}} \lambda \frac{q_{\mathrm{atm}}-q_{\mathrm{ac}}}{r_{\mathrm{aw}}}=W_{\text {roof }} Q_{E, \text { roof }}+\left(1-W_{\text {roof }}\right) \\
& \times\left[f_{\text {prvrd }} Q_{E, \text { prvrd }}+\left(1-f_{\text {prvrd }}\right) Q_{E \text {,imprvrd }}\right],
\end{aligned}
$$

where $Q_{E}$ is latent heat flux $\left(\mathrm{W} \mathrm{m}^{-2}\right), q_{g}$ is the specific humidity at each urban surface $\left(\mathrm{kg} \mathrm{kg}^{-1}\right)$, and $\lambda$ is the latent heat of vaporization (or sublimation) $\left(\mathrm{J} \mathrm{kg}^{-1}\right)$. Note that $Q_{E \text {,sunwall }}=Q_{E \text {,shdwall }}=0$. The UCL air specific humidity is then

$$
q_{\mathrm{ac}}=\frac{c_{a}^{w} q_{\mathrm{atm}}+c_{\mathrm{roof}} f_{\mathrm{wet}, \mathrm{roof}} q_{\mathrm{g}, \mathrm{roof}}+c_{\mathrm{prvrd}} q_{g, \text { prvrd }}+c_{\text {imprvrd }} f_{\mathrm{wet}, \text { imprvrd }} q_{g, \text { imprvrd }}}{c_{a}^{w}+f_{\mathrm{wet}, \text { roof }} c_{\text {roof }}+c_{\text {prvrd }}+f_{\text {wet,imprvrd }} c_{\text {imprvrd }}}
$$

where $c_{a}^{w}$ is the latent heat conductance from the canopy air to the atmosphere $\left(1 / r_{\text {aw }}\right)$ and $c_{\text {roof }}, c_{\text {prvrd }}$, and $c_{\text {imprord }}$ are the weighted heat conductances from urban surfaces to UCL air. The aerodynamic resistances to sensible and latent heat transfer between the UCL air and the overlying atmosphere $\left(r_{\mathrm{ah}}, r_{\mathrm{aw}}\right)$ depend on stability as in CLM3 [see Eqs. (5.56) and (5.57) in Oleson et al. 2004]. The specific humidities of the roof and impervious road surfaces, $q_{g \text {,roof }}$ and $q_{g \text {,imprvrd }}$, are set to the saturated specific humidity evaluated at their respective surface temperatures.

The term $f_{\text {wet }}$ is the fraction of the roof or impervious road surface that is wet. If dew occurs $\left(q_{\mathrm{ac}}-q_{g}>0\right)$, then $f_{\text {wet }}=1$. If snow depth $z_{\text {sno }}>0, f_{\text {wet }}$ is determined from

$$
f_{\text {wet }}=\frac{z_{\text {sno }}}{0.05} \leq 1
$$

In the absence of snow,

$$
f_{\text {wet }}=\left(\frac{w_{\text {liq }, 1}+w_{\text {ice }, 1}}{w_{\text {pond,max }}}\right)^{2 / 3} \leq 1,
$$

where $w_{\text {liq, } 1}$ and $w_{\text {ice, } 1}$ are the mass of liquid water and ice $\left(\mathrm{kg} \mathrm{m}^{-2}\right)$ stored on top of the urban surface and $w_{\text {pond,max }}$ is the maximum amount of water that the surface can hold $\left(1 \mathrm{~kg} \mathrm{~m}^{-2}\right)$. This latter formulation is analogous to the treatment of the wetted fraction of the vegetated canopy in CLM3 (Oleson et al. 2004).

The approach used here to represent pervious surfaces is different from many urban schemes designed for use within mesoscale and global models. Most urban schemes use a separate land surface model scheme to represent the effects of pervious surfaces on urban climate (Lemonsu and Masson 2002). In our approach, the pervious surface is an integral part of the urban system and interacts directly with UCL air properties such as temperature and specific humidity. Yet, implementation of a sophisticated scheme for the pervious surface, such as the vegetation scheme in CLM3, within the urban canyon is problematic because of computational and data requirements. Here, we choose a simplified bulk parameterization scheme to represent latent heat flux from pervious urban surfaces. The pervious road specific humidity $q_{g, \text { prvrd }}$ is evaluated as a function of the wetness of the total soil column. This allows all of the soil moisture potentially to be available for evaporation.

The system of Eqs. (33)-(46) is solved iteratively, where stability, fluxes, aerodynamic resistances, and UCL air properties are evaluated at each iteration. The sensible heat and water vapor fluxes are based on the urban surface temperature from the previous time step $T_{g}^{n}$ and are used to force the soil temperature equations (section 2e). The solution of the soil temperature equations yields a new surface temperature $T_{g}^{n+1}$ that is used to update the turbulent fluxes. The storage heat flux $Q_{S}$ for each urban surface is determined as a residual from the updated fluxes:

$$
Q_{S, u}=\vec{S}_{u}-\vec{L}_{u}-Q_{H, u}-Q_{E, u} .
$$

\section{e. Roof, wall, road, and snow temperatures}

The solution for impervious and pervious roads follows the solution for CLM3 soils where the heat conduction equation is solved numerically for a 10-layer column with up to 5 overlaying layers of snow with boundary conditions of $Q_{S, u}$ as the heat flux into the surface layer from the overlying atmosphere and zero heat flux at the bottom of the soil column (Oleson et al. 
TABLE 1. Morphological input data required for the urban model and values used for the Mexico City and Vancouver simulations.

\begin{tabular}{llcc}
\hline \multicolumn{1}{c}{ Data } & Symbol & Mexico City & Vancouver \\
\hline Canyon height-to-width ratio* & $H / W$ & 1.18 & 0.39 \\
Roof fraction* & $W_{\text {roof }}$ & 0.55 & 0.51 \\
Pervious road fraction** & $f_{\text {prvrd }}$ & 0.04 & 0.11 \\
Roof thickness* (m) & $\Delta z_{\text {roof }, i}$ & $i=1, \ldots, 10: 0.0185$ & $i=1, \ldots, 10: 0.007$ \\
Wall thickness* (m) & $\Delta z_{\text {walls }, i}$ & $i=1, \ldots, 10: 0.045$ & $i=1, \ldots, 10: 0.02$ \\
Impervious road thickness* $(\mathrm{m})$ & $\Delta z_{\text {imprvrd }, i}$ & $i=1, \ldots, 5: 0.03$, & $i=1, \ldots, 5: 0.03$, \\
Building height* (m) & & $i=6, \ldots, 10:$ Soil & $i=6, \ldots, 10:$ Soil \\
Lat, lon & $H$ & 18.8 & 5.8 \\
& $\phi, \theta$ & $19.43^{\circ} \mathrm{N}, 260.87^{\circ} \mathrm{E}$ & $49.27^{\circ} \mathrm{N}, 236.90^{\circ} \mathrm{E}$ \\
\hline
\end{tabular}

* MG02.

** Derived from plan area fraction in Grimmond and Oke (1999b).

2004). The roof consists of a 10-layer structure in addition to a 5-layer snowpack; however, the bottom boundary condition is a nonzero flux calculated from the temperature difference between the inner layer and an internal building surface temperature $T_{\mathrm{iB}}$. The $T_{\mathrm{iB}}$ is determined from a weighted combination of the inner layer walls and roof temperatures. Upper and lower limits on $T_{\mathrm{iB}}$ may be prescribed to simulate heating or air-conditioning. The walls are modeled similarly to roofs except for the absence of ponded water or snow.

\section{f. Hydrology}

The pervious road hydrology includes snow accumulation and melt, water transfer between snow layers, infiltration, surface runoff, subsurface drainage, and redistribution within the soil column to simulate changes in snow water, soil water, and soil ice. These processes are parameterized as in CLM3 (Oleson et al. 2004). The roof and impervious road are hydrologically inactive except for their ability to intercept and store a limited amount of liquid precipitation $\left(1 \mathrm{~kg} \mathrm{~m}^{-2}\right)$, and they store snow. The liquid water in excess of this storage capacity is routed to surface runoff. No subsurface drainage is allowed. The sunlit and shaded walls are hydrologically inactive.

\section{Evaluation}

MG02 evaluated the TEB model for two urban sites (Mexico City and Vancouver), as did Best et al. (2006) for the Met Office Surface Exchange Scheme (MOSES). Here, we closely follow the evaluation methods of the Masson study and evaluate the model's performance with observed data, contrasting it with TEB's performance where appropriate. The model is run uncoupled from the atmospheric model and is forced by observations of atmospheric variables. The sites are the historic city core of Mexico City, Mexico (hereinafter referred to as Me93) and a light industrial area in Vancouver, British Columbia, Canada (V192).

\section{a. Mexico City}

Meteorological and surface flux data were collected for Mexico City for 1-7 December 1993 (Oke et al. 1999). The observation site is located on the western edge of the historic city core. The surface cover within the vicinity primarily consists of large buildings and impervious surfaces such as roads and squares. Vegetation cover is nearly negligible, but additional small sources of moisture include vehicle combustion, air-conditioning, and street washing. The mean building height within the flux source area is about $18 \mathrm{~m}$, and the average $H / W$ is 1.18 . Most buildings are made of stone or concrete with roofs of concrete, tar, sheet metal, or tile. Roads are paved with concrete or asphalt or are surfaced with tiles, cobble, or flagstones. Descriptions of the measurements can be found in Oke et al. (1999) and MG02.

The urban model was configured with parameter values shown in Tables 1, 2, and 3. Roughness length was set to $2.2 \mathrm{~m}$ per MG02, and displacement height was set to an average of the values calculated by Grimmond and Oke (1999a; $10.9 \mathrm{~m})$. Incoming solar radiation was not measured at the site but was taken from data collected by the nearby ( $\sim 13 \mathrm{~km}$ south) Institute of Geophysics, Universidad Nacional Autónoma de México (MG02). Incoming longwave radiation was not measured and was determined from the equation of Prata (1996) based on the recommendation of Offerle et al. (2003). The deep (10th layer) temperatures for pervious and impervious road were initialized to $295.16 \mathrm{~K}$ (MG02), and top-layer temperatures were initialized to the initial air temperature $(289.46 \mathrm{~K})$. Temperatures for intermediate layers were linearly interpolated. Roof and wall temperatures were initialized to the initial air temperature. Soil moisture for pervious road was set to 
TABLE 2. Thermal input data required for the urban model and values used for the Mexico City and Vancouver simulations. Thermal parameters of the soil for the pervious and impervious road are determined from soil texture (Oleson et al. 2004).

\begin{tabular}{|c|c|c|c|}
\hline Data & Symbol & Mexico City & Vancouver \\
\hline \multirow{4}{*}{$\begin{array}{l}\text { Roof thermal conductivity }{ }^{\mathrm{a}} \\
\qquad\left(\mathrm{W} \mathrm{m} \mathrm{m}^{-1} \mathrm{~K}^{-1}\right)\end{array}$} & $\lambda_{\text {roof }, i}$ & $i=1: 0.2$ (asphalt roll) & $i=1, \ldots, 4: 1.4$ (gravel) \\
\hline & & $i=2, \ldots, 6: 0.93($ concrete $/$ stone $)$ & $i=5: 0.03$ (insulation) \\
\hline & & $i=7, \ldots, 9: 0.03$ (insulation) & $i=6, \ldots, 10: 1.51$ (dense concrete) \\
\hline & & $i=10: 0.16($ gypsum $)$ & \\
\hline \multirow{3}{*}{$\begin{array}{l}\text { Wall thermal conductivity } \\
\left(\mathrm{W} \mathrm{m}^{-1} \mathrm{~K}^{-1}\right)\end{array}$} & $\lambda_{\mathrm{wall}, i}$ & $i=1, \ldots, 100.88($ stone $/$ window $)$ & $i=1,2: 1.51$ (dense concrete) \\
\hline & & & $i=3, \ldots, 9: 0.67$ (concrete) \\
\hline & & & $i=10: 1.51($ dense concrete $)$ \\
\hline \multirow{3}{*}{$\begin{array}{l}\text { Impervious road thermal } \\
\text { conductivity }^{\mathrm{b}}\left(\mathrm{W} \mathrm{m}^{-1} \mathrm{~K}^{-1}\right)\end{array}$} & $\lambda_{\text {imprvrd, } i}$ & $i=1,2: 0.82($ asphalt/concrete $)$ & $i=1,2: 0.82($ asphalt/concrete $)$ \\
\hline & & $i=3, \ldots, 5: 2.10($ stone aggregate $)$ & $i=3, \ldots, 5: 2.10$ (stone aggregate) \\
\hline & & $i=6, \ldots, 10:$ soil texture & $i=6, \ldots, 10:$ soil texture \\
\hline $\begin{array}{l}\text { Pervious road thermal } \\
\text { conductivity }\left(\mathrm{W} \mathrm{m}^{-1} \mathrm{~K}^{-1}\right)\end{array}$ & $\lambda_{\text {prvrd }, i}$ & Soil texture & Soil texture \\
\hline \multirow{4}{*}{$\begin{array}{l}\text { Roof volumetric heat capacity } \\
\qquad\left(\mathrm{MJ} \mathrm{m}^{-3} \mathrm{~K}^{-1}\right)\end{array}$} & $c_{\text {roof }, i}$ & $i=1: 1.76$ (asphalt roll) & $i=1, \ldots, 4: 1.76$ (gravel) \\
\hline & & $i=2, \ldots, 6: 1.5($ concrete $/$ stone $)$ & $i=5: 0.04$ (insulation) \\
\hline & & $i=7, \ldots, 9: 0.25$ (insulation) & $i=6, \ldots, 10: 2.21$ (dense concrete) \\
\hline & & $i=10: 0.87($ gypsum $)$ & \\
\hline \multirow{3}{*}{$\begin{array}{l}\text { Wall volumetric heat capacity } \\
\qquad\left(\mathrm{MJ} \mathrm{m}^{-3} \mathrm{~K}^{-1}\right)\end{array}$} & $c_{\mathrm{wall}, i}$ & $i=1, \ldots, 10: 1.54($ stone $/$ window $)$ & $i=1,2: 2.11($ dense concrete $)$ \\
\hline & & & $i=3, \ldots, 9: 1.00$ (concrete) \\
\hline & & & $i=10: 2.11($ dense concrete $)$ \\
\hline \multirow{3}{*}{$\begin{array}{l}\text { Impervious road volumetric heat } \\
\text { capacity }^{\mathrm{b}}\left(\mathrm{MJ} \mathrm{m}^{-3} \mathrm{~K}^{-1}\right)\end{array}$} & $c_{\text {imprvrd, } i}$ & $i=1,2: 1.74$ (asphalt/concrete) & $i=1,2: 1.74($ asphalt/concrete $)$ \\
\hline & & $i=3, \ldots, 5: 2.00($ stone aggregate $)$ & $i=3, \ldots, 5: 2.00$ (stone aggregate) \\
\hline & & $i=6, \ldots, 10:$ soil texture & $i=6, \ldots, 10:$ soil texture \\
\hline $\begin{array}{l}\text { Pervious road volumetric heat } \\
\text { capacity }^{\mathrm{c}}\left(\mathrm{MJ} \mathrm{m}^{-3} \mathrm{~K}^{-1}\right)\end{array}$ & $c_{\text {prvrd }, i}$ & Soil texture & Soil texture \\
\hline $\begin{array}{l}\text { Max interior building } \\
\text { temperature }(\mathrm{K})\end{array}$ & $T_{\mathrm{iB}, \max }$ & Allowed to evolve freely & Allowed to evolve freely \\
\hline $\begin{array}{l}\text { Min interior building } \\
\text { temperature }(\mathrm{K})\end{array}$ & $T_{\mathrm{iB}, \min }$ & Allowed to evolve freely & Allowed to evolve freely \\
\hline Soil texture $(\%)$ & $\%$ sand, \% clay & $50 \%$ sand, $40 \%$ clay & $50 \%$ sand, $40 \%$ clay \\
\hline
\end{tabular}

a M02.

${ }^{\mathrm{b}}$ Nonsoil is from MG02, soil is from Oleson et al. (2004).

${ }^{c}$ Oleson et al. (2004).

$0.3 \mathrm{~mm}^{3} \mathrm{~mm}^{-3}$. No anthropogenic fluxes were prescribed.

Infrared thermometers were used to measure the surface temperature of a roof and the floor of an eastwest- and a north-south-oriented canyon adjacent to the site (Oke et al. 1999). The average diurnal cycle of the local-scale model roof and road temperatures are compared with observed microscale temperatures for the Me93 site in Fig. 6. Observed wall temperatures are not available. The model generally captures the observed diurnal cycle of the roof and average canyon floor temperatures. The nighttime roof temperature is particularly well simulated in terms of both magnitude and cooling rate. However, similar to the TEB model, the model exhibits faster warming and cooling rates
TABLE 3. Radiative input data required for the urban model and values used for the Mexico City and Vancouver simulations. Albedos do not vary between direct and diffuse $(b)$ and visible and near-infrared $(\Lambda)$. Values are from MG02.

\begin{tabular}{|c|c|c|c|}
\hline \multirow[b]{2}{*}{ Data } & \multicolumn{3}{|c|}{ Mexico } \\
\hline & Symbol & City & Vancouver \\
\hline Roof emissivity & $\varepsilon_{\text {roof }}$ & 0.90 & 0.92 \\
\hline Impervious road emissivity & $\varepsilon_{\text {imprvrd }}$ & 0.95 & 0.95 \\
\hline Pervious road emissivity & $\varepsilon_{\text {prvrd }}$ & 0.95 & 0.95 \\
\hline Wall emissivity & $\varepsilon_{\text {wall }}$ & 0.85 & 0.90 \\
\hline Roof albedo & $\alpha_{\text {roof, } \Lambda}^{b}$ & 0.20 & 0.12 \\
\hline Wall albedo & $\alpha_{\text {walls, } \Lambda}^{b}$ & 0.25 & 0.50 \\
\hline Impervious road albedo & $\alpha_{\text {imprvrd, } \Lambda}^{b}$ & 0.08 & 0.08 \\
\hline Pervious road albedo & $\alpha_{\text {prvrd, } \Lambda}^{b}$ & 0.08 & 0.08 \\
\hline
\end{tabular}


Roof

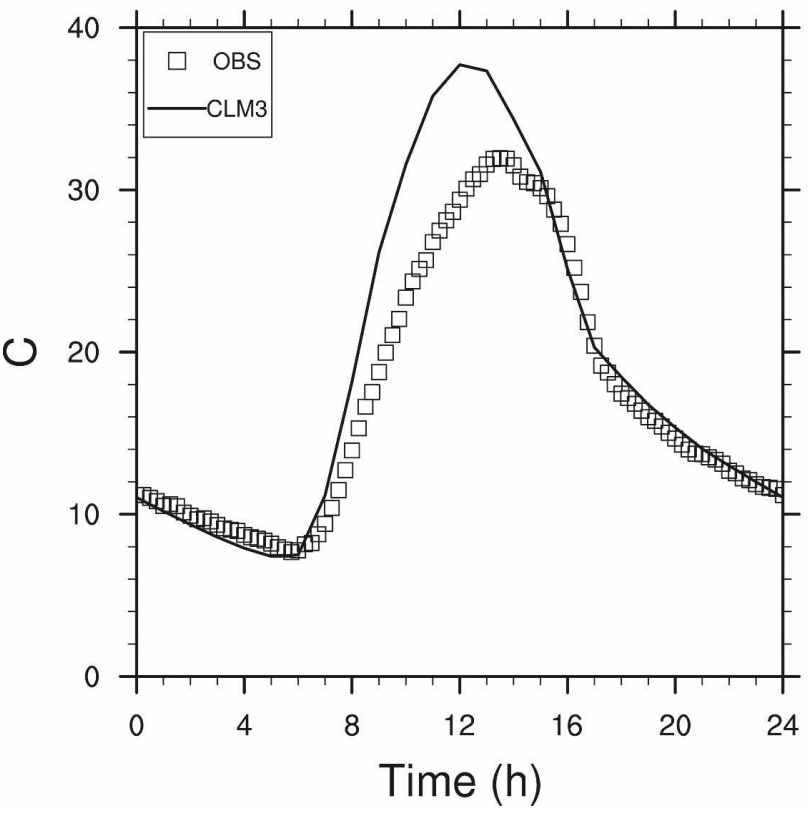

Road

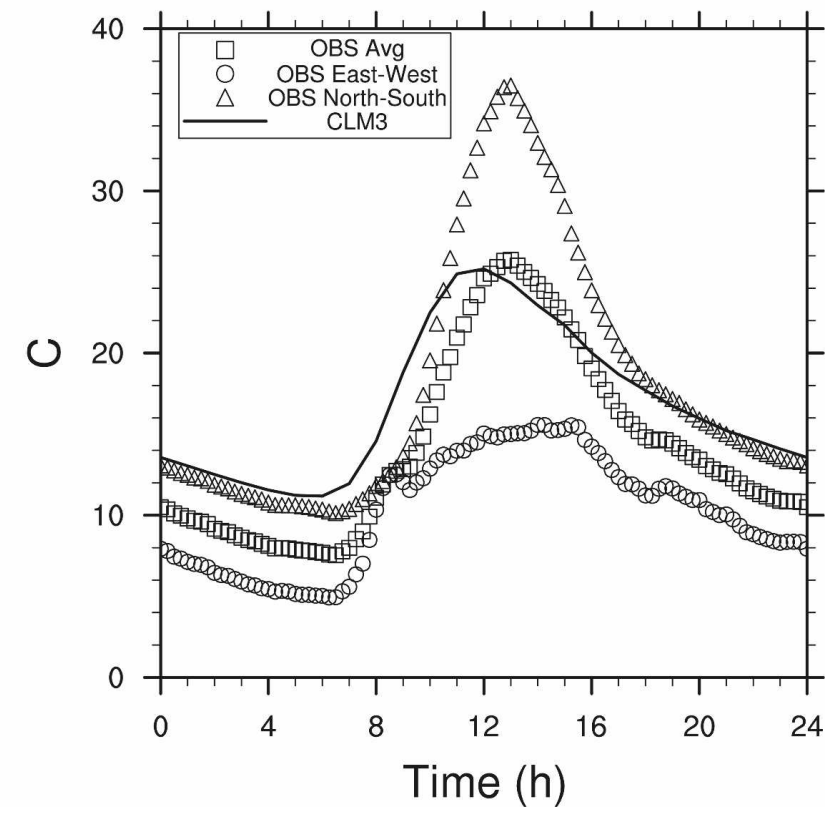

Wall

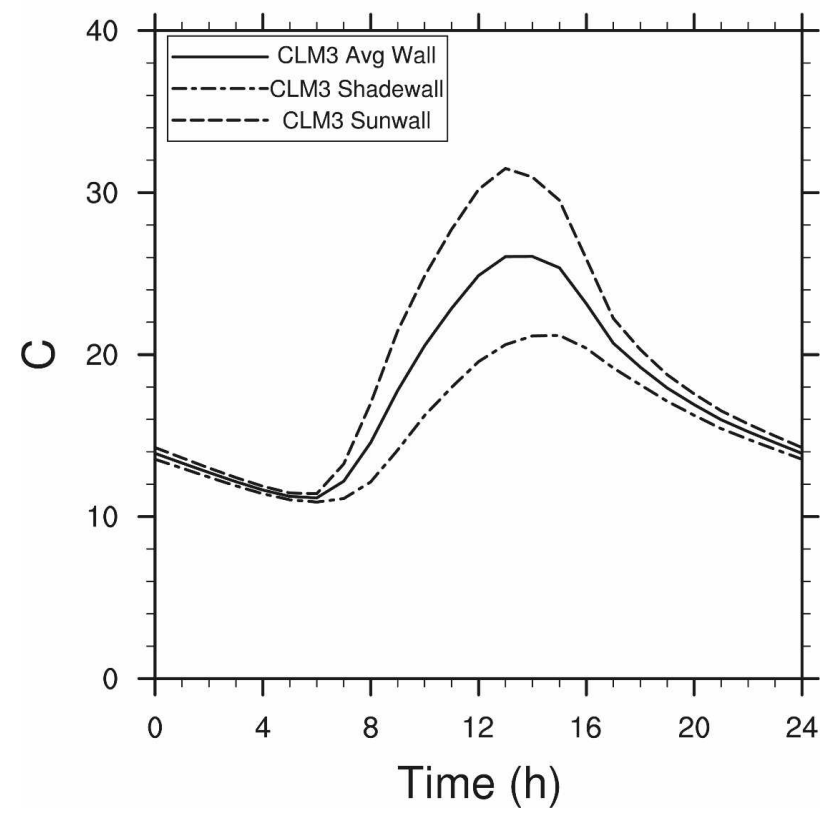

FIG. 6. Average diurnal cycle of simulated and observed surface temperatures $\left({ }^{\circ} \mathrm{C}\right)$ for Me93 for days $336-341$ (2-7 Dec 1993). The area viewed by the sensors for the observed east-west and north-south "road" include portions of the lower walls as well as the road.

during insolation than are observed and the peak roof temperature is positively biased by about $6 \mathrm{~K}$. The simulated road temperature is about $4 \mathrm{~K}$ too high at night, but the peak daytime temperature is within $1 \mathrm{~K}$ of observed. We note that there is uncertainty in the canyon floor observations because the sensors also see the lower part of the walls as well as the road. In gen- eral, these results are similar to those obtained by MG02 for the TEB model. CLM3 does a better job of capturing the nighttime roof temperature, and the daytime roof temperature is $2 \mathrm{~K}$ lower than TEB, which is in better agreement with observations. The nighttime and daytime road temperatures are also lower than TEB, which agrees with observations. However, TEB 

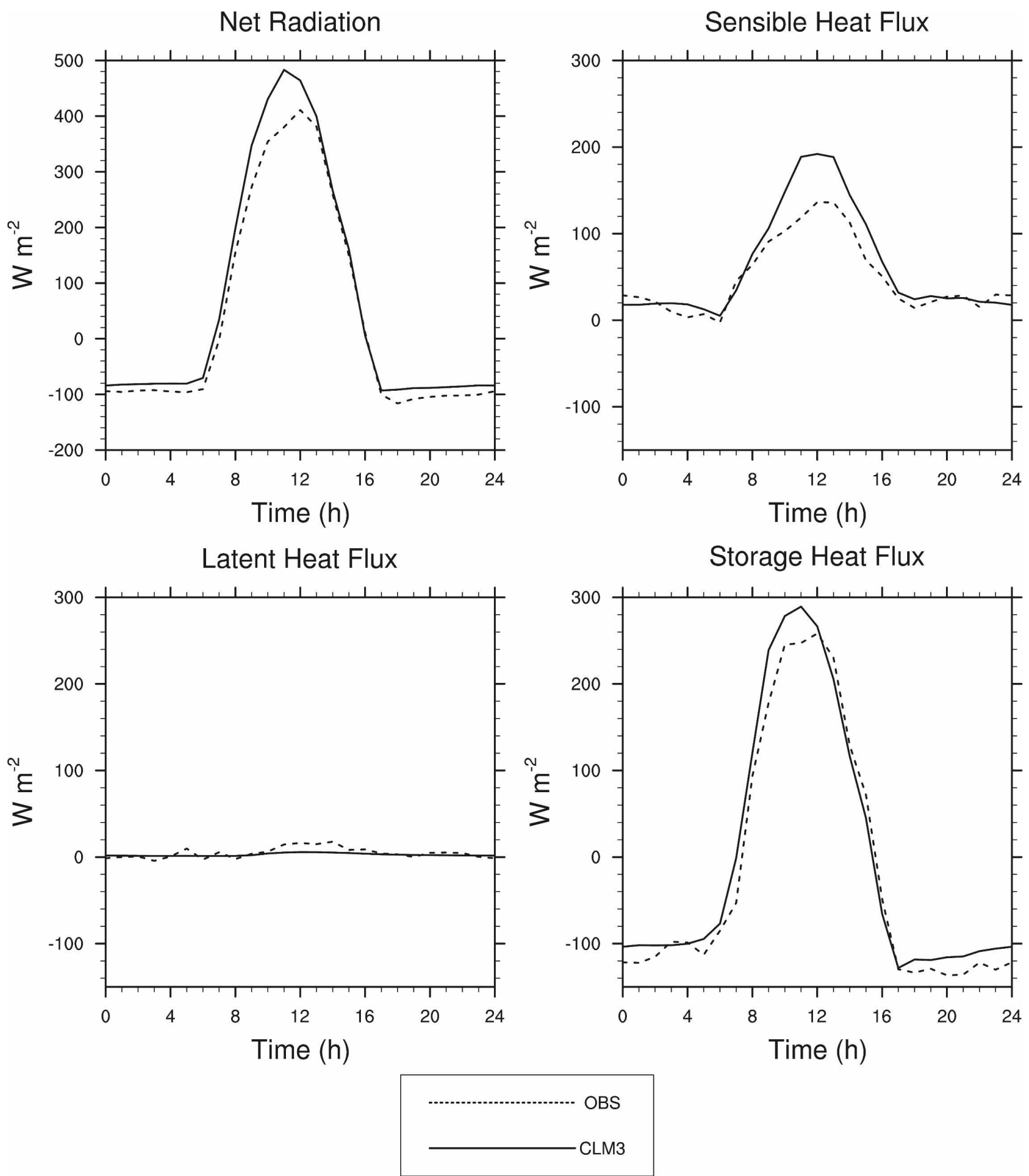

FIG. 7. Average diurnal cycle of simulated and observed heat fluxes for Me93 for days 336-341 (2-7 Dec 1993).

simulates better the phase of the diurnal cycle. As noted by MG02, these results are considered to be reasonable, given the mismatch between the variables modeled on a local scale and the microscale measurements of these variables.
In general, the urban model does a good job of reproducing net radiation and sensible, latent, and storage heat fluxes for the Me93 site (Fig. 7 and Table 4). Daytime surface energy balance at this site is dominated by storage heat flux, which is generally well cap- 
TABLE 4. Summary statistics of simulated and observed net radiation $Q^{*}$ and sensible heat $Q_{H}$, latent heat $Q_{E}$, and storage storage $Q_{S}$ fluxes for Me93 for days 336-341 (2-7 Dec 1993). Here $N$ is the number of data points, bias is mean of model - mean of observations $\left(\mathrm{W} \mathrm{m}^{-2}\right)$, RMSE is the root-mean-square error (W $\left.\mathrm{m}^{-2}\right), r^{2}$ is the coefficient of determination, and intercept is the $y$ intercept of the regression line $\left(\mathrm{W} \mathrm{m}^{-2}\right)$.

\begin{tabular}{llcccc}
\hline \hline & Heat flux & $Q^{*}$ & $Q_{H}$ & $Q_{E}$ & $Q_{S}$ \\
\hline Overall & Model & 68 & 63 & 3 & 3 \\
$(N=123)$ & Obs & 43 & 50 & 5 & -11 \\
& Bias & 25 & 13 & -2 & 14 \\
& RMSE & 44 & 34 & 10 & 36 \\
& $r^{2}$ & 0.99 & 0.81 & 0.28 & 0.96 \\
Daytime $\left(Q^{*} \geq 0\right)$ & Intercept & 24 & 2 & 2 & 16 \\
$(N=48)$ & Model & 299 & 131 & 4 & 164 \\
& Obs & 256 & 96 & 9 & 151 \\
& Bias & 43 & 35 & -5 & 13 \\
Nighttime $\left(Q^{*}<0\right)$ & RMSE & 65 & 48 & 12 & 45 \\
$(N=75)$ & Model & -80 & 19 & 2 & -101 \\
& Obs & -96 & 19 & 2 & -117 \\
& Bias & 16 & 0 & 0 & 16 \\
& RMSE & 19 & 20 & 8 & 29 \\
& $r^{2}$ & 0.76 & 0.27 & 0.10 & 0.35 \\
& Intercept & 9 & 12 & 2 & -40 \\
\hline
\end{tabular}

tured by the model with respect to amplitude and phase. The simulated phase of the sensible heat flux appears to be reasonable, although the daytime peak is overestimated by $50-60 \mathrm{~W} \mathrm{~m}^{-2}$. Some of this overestimation is likely due to excessive net radiation (40-100 $\mathrm{W} \mathrm{m}{ }^{-2}$ during the middle of the day) simulated by the model and lower-than-observed latent heat flux. The deficit in latent heat flux is likely due in part to the sources not modeled here, as mentioned above.

The very high daytime $Q_{S} / Q^{*}$ ratio of 0.59 (Table 4) noted by Oke et al. (1999), which is attributed to the large thermal admittance of the site, is simulated well by the model $(0.55)$. The observed nighttime $Q_{S} / Q^{*}$ ratio is 1.22 , which supports a positive nighttime sensible heat flux of $19 \mathrm{~W} \mathrm{~m}^{-2}$. Although the net radiation loss estimated by the model is smaller than observed, the simulated nighttime $Q_{S} / Q^{*}$ ratio (1.26) is similar to the observed because the release of stored heat is also underestimated. This supports a positive sensible heat flux at night that on average is the same as the observed flux.

\section{b. Vancouver}

Meteorological, surface flux, and temperature data were collected for a light industrial site in Vancouver (V192) for 11-25 August 1992 (Voogt and Grimmond 2000; Grimmond and Oke 2002). The site is character- ized by 1-3-story buildings with flat roofs used for warehousing and light industry. Vegetation cover is small (plan area cover $<5 \%$ ). The mean building height within the flux source area is about $6 \mathrm{~m}$, and the average $H / W$ is 0.39 . Most buildings are made of concrete, and roads and pathways are made of asphalt. Descriptions of the measurements can be found in Voogt and Grimmond (2000), Grimmond and Oke (2002), and MG02.

The urban model was configured with parameter values shown in Tables 1, 2, and 3. Roughness length was set to $0.35 \mathrm{~m}$ per MG02, and displacement height was set to an average of the values calculated by Grimmond and Oke (1999a; $3.5 \mathrm{~m})$. Incoming solar radiation was taken from data collected by the Canadian Atmospheric Environment Service at the Vancouver International Airport (8 km south of V192; MG02). Incoming longwave radiation was determined from Prata (1996). The deep (10th layer) "soil" temperatures for pervious and impervious road were initialized to 293.16 $\mathrm{K}$ (MG02), and top-layer temperatures were initialized to the initial air temperature $(297.56 \mathrm{~K})$. Temperatures for intermediate layers were linearly interpolated. Roof and wall temperatures were initialized to the initial air temperature. Soil moisture for pervious road was set to $0.3 \mathrm{~mm}^{3} \mathrm{~mm}^{-3}$. No anthropogenic fluxes were prescribed.

The observed data are divided into two periods for evaluation: six sunny days characterized by a sea breeze in the early afternoon (days 225-231; 13-19 August, denoted as period 1) and five more cloudy days characterized by a much weaker late afternoon sea breeze (days 232-236; 20-24 August, denoted as period 2). Although the simulated roof temperature is within $5 \mathrm{~K}$ of the observed peak daytime temperature for both periods, the simulated nighttime temperature is too warm by $15 \mathrm{~K}$, such that the diurnal temperature range is underestimated by about $20 \mathrm{~K}$ (Figs. 8 and 9). As noted by MG02, this poor performance is somewhat expected because the roof where the microscale surface temperatures were observed is constructed of materials with different properties (steel overlaid with gravel) than the majority of roofs within the source region (concrete overlaid with insulation and gravel).

Airborne infrared measurements of roofs, walls, and roads, representative of the local-scale flux source area, were conducted during one day (one measurement each at 1000, 1400, and 1700 Pacific daylight time (Voogt and Grimmond 2000). The model performs better when compared with the local-scale roof airborne measurements for day 228 (Fig. 10). Simulated daytime roof temperatures are within $1-5 \mathrm{~K}$ of observed. There are no observed local-scale roof nighttime tempera- 
Roof

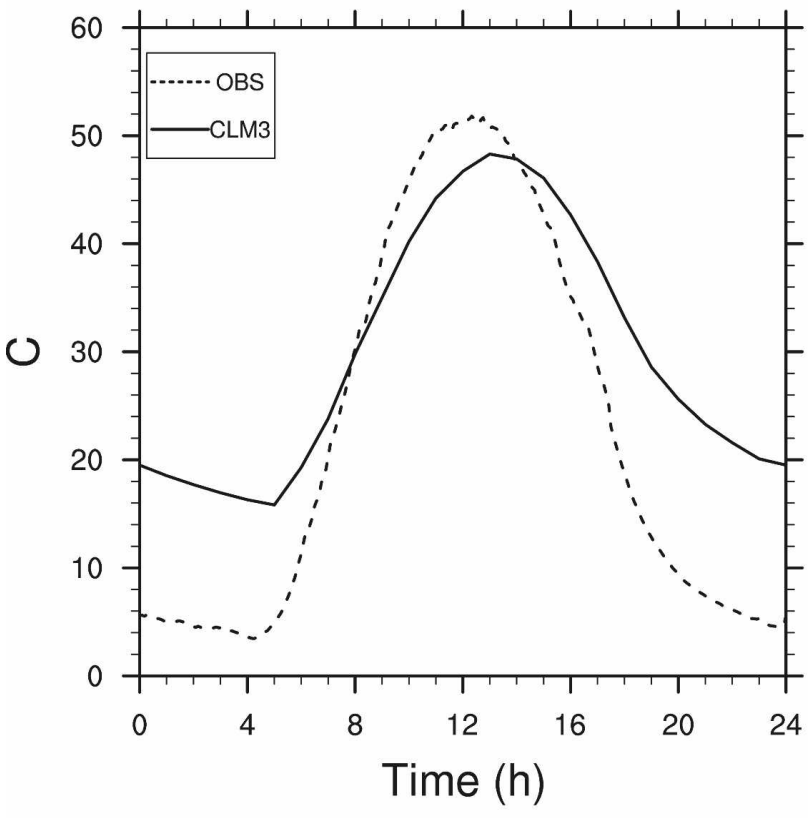

Wall

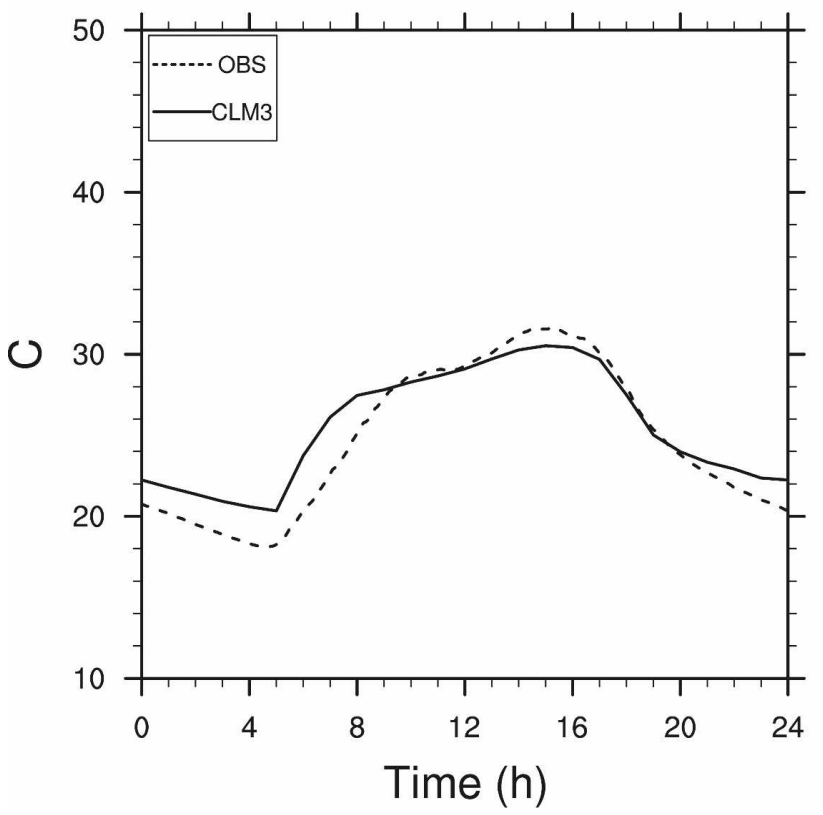

Road

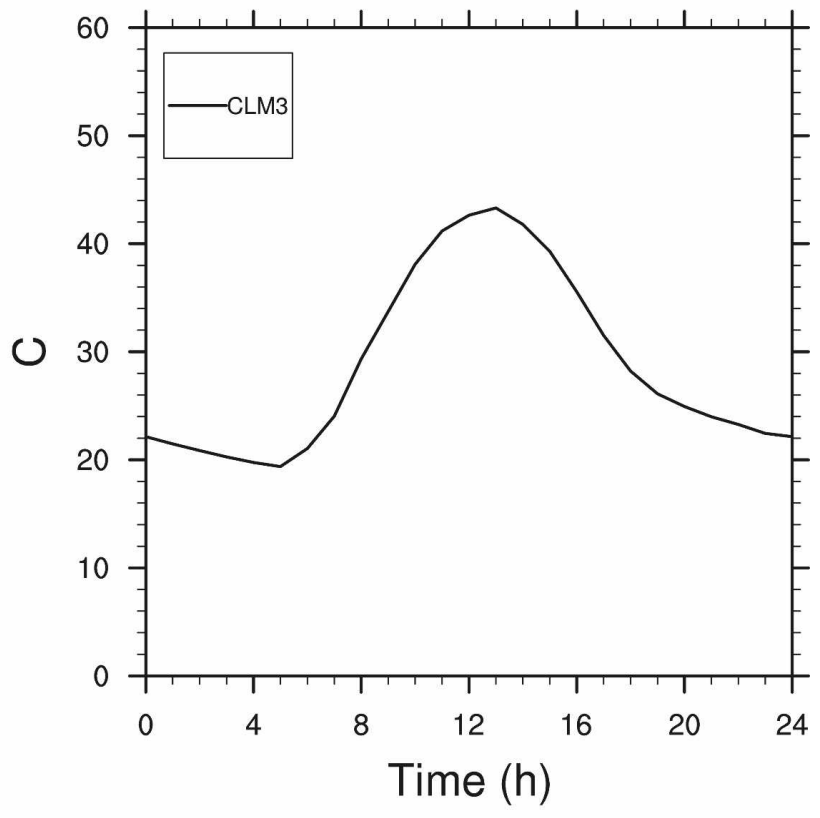

Wall

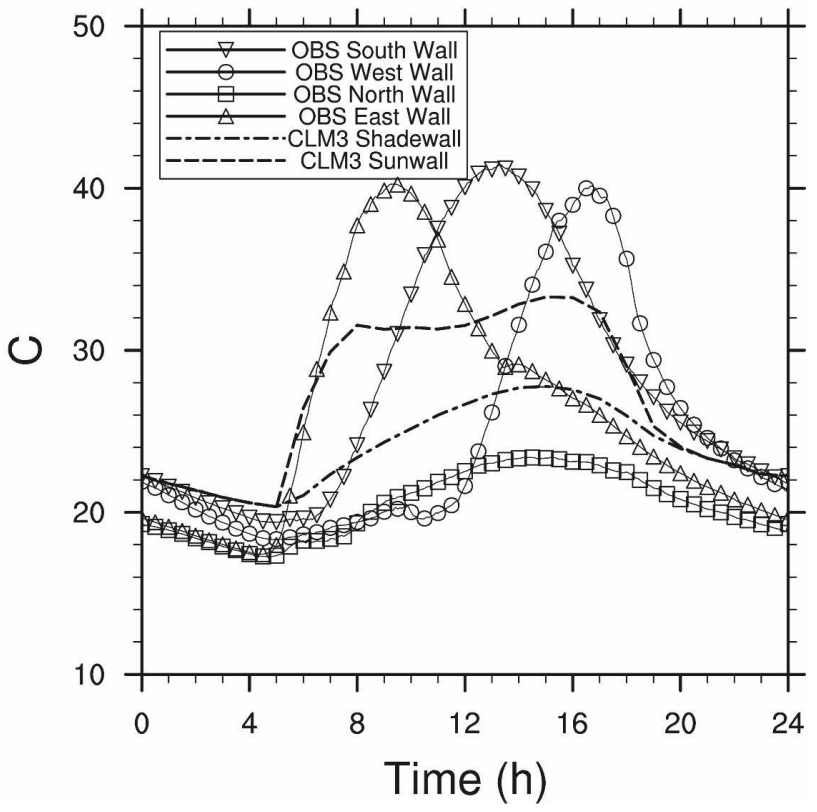

FIG. 8. Average diurnal cycle of simulated and observed surface temperatures $\left({ }^{\circ} \mathrm{C}\right)$ for V192 for days 225-231 (13-19 Aug 1992).

tures; however, note that the model is warmer than TEB by about $6 \mathrm{~K}$. A similar difference is found during daytime, which agrees better with observations. More detailed model intercomparisons would be required to resolve the cause of this difference. The local-scale airborne measurements of the road on day 228 indicate that the simulated road temperature is too warm by $2 \mathrm{~K}$ in the morning and late afternoon and by $6 \mathrm{~K}$ in early afternoon. This result is similar to that of the TEB model.

Microscale wall surface temperatures were sampled using a set of fixed infrared sensors on buildings near the flux observation tower (Voogt and Grimmond 2000). The simulated average daytime wall temperature (arithmetic mean of sunlit and shaded walls) compares favorably to the average of the observed wall tempera- 
Roof

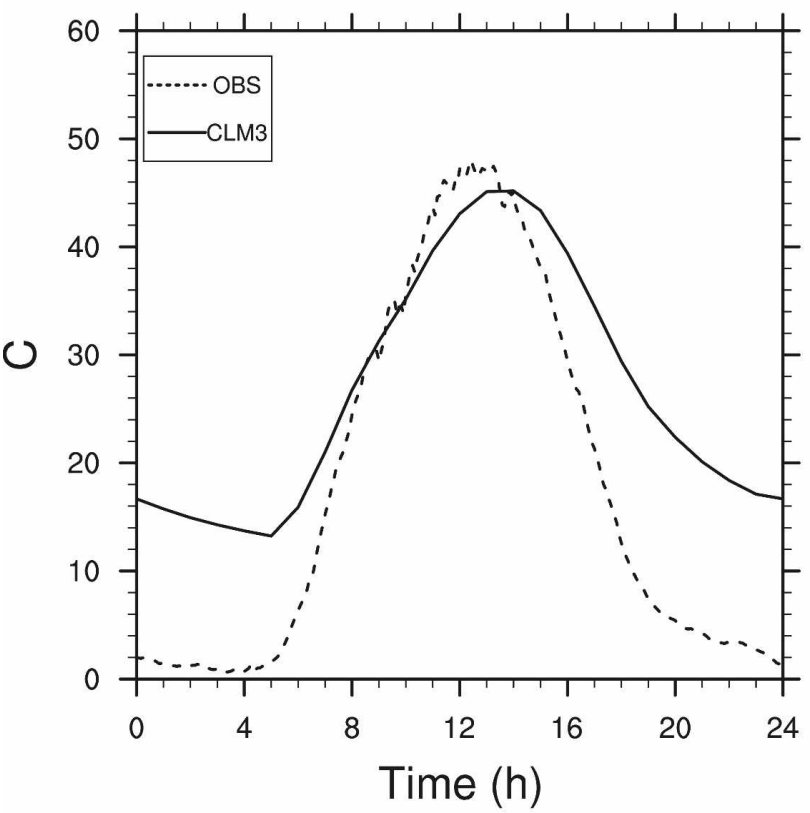

Wall

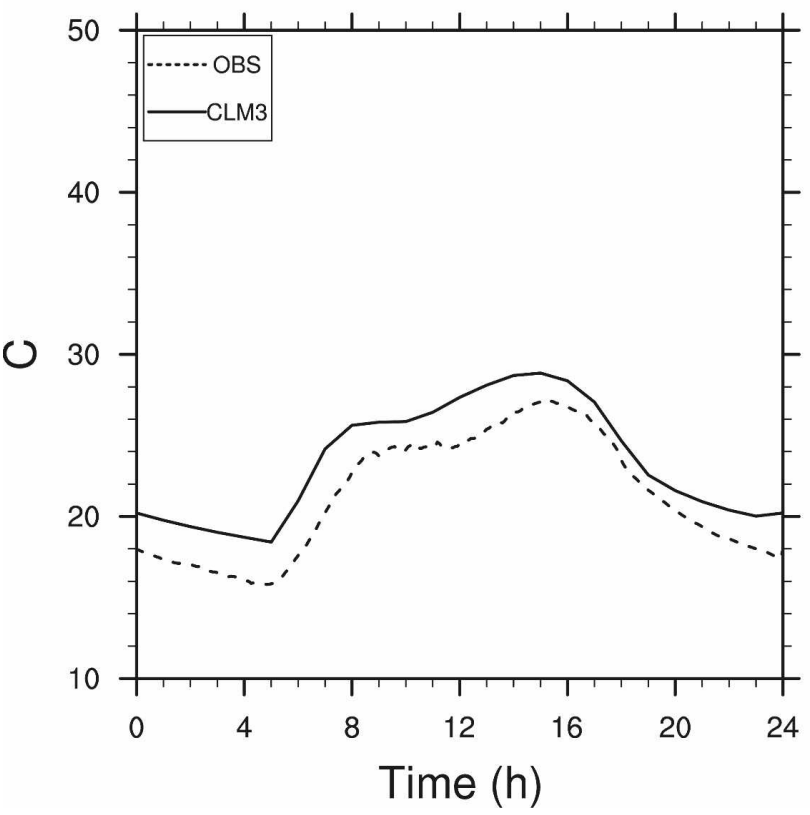

Road
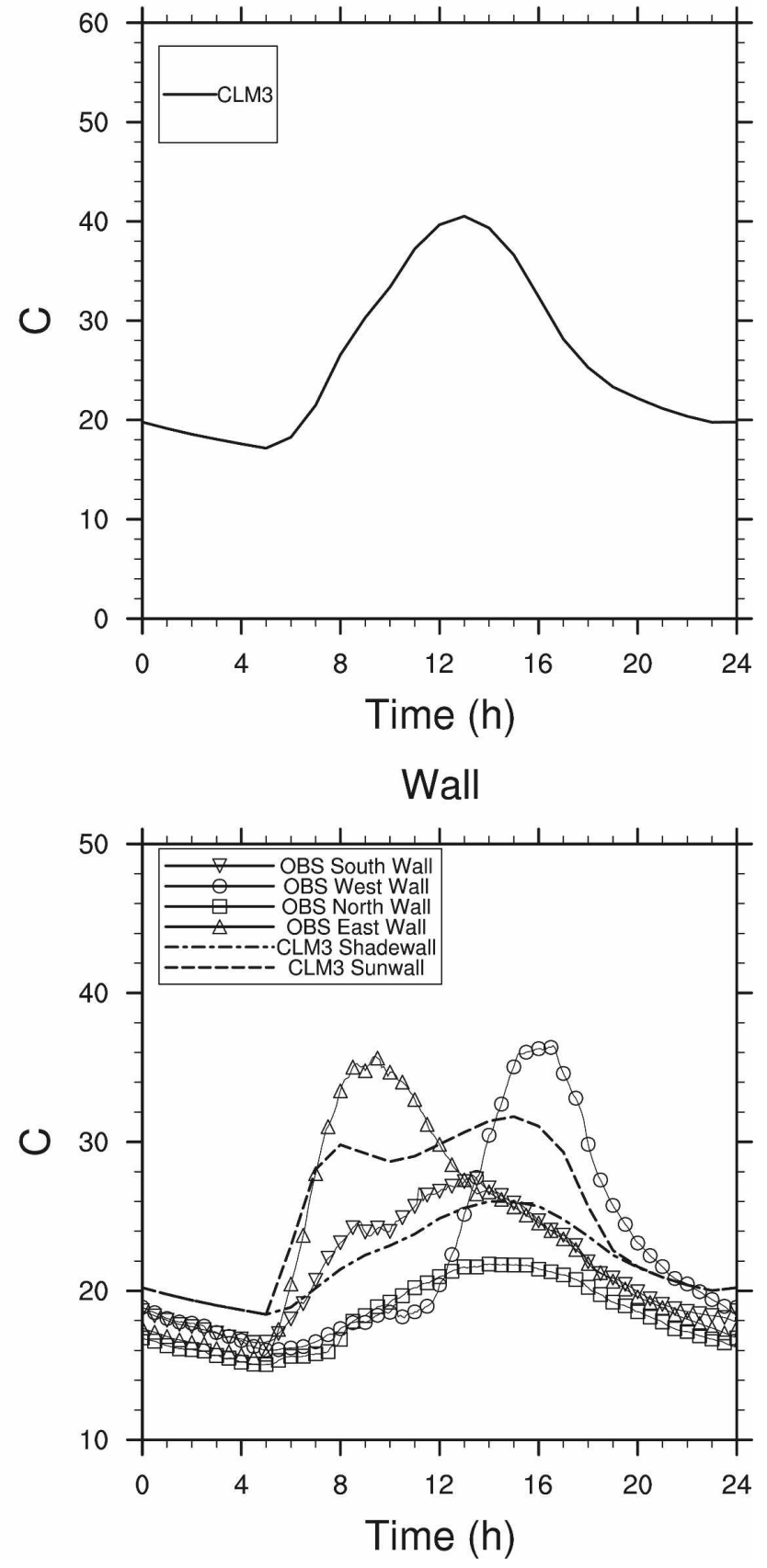

FIG. 9. Average diurnal cycle of simulated and observed surface temperatures $\left({ }^{\circ} \mathrm{C}\right)$ for V192 for days 232-236 (20-24 Aug 1992).

tures, including a good simulation of the timing of early-morning and late-afternoon peak temperatures (Figs. 8 and 9). In period 1, the decrease in the observed late-morning warming rate and increase in the early afternoon is generally captured by the model, although the timing appears to be off by about an hour. In period 2 , temperatures are biased to be too warm by about 2 $\mathrm{K}$, but simulated heating and cooling rates are compa- rable to observations. The local-scale airborne measurements for day 228 indicate that the simulated wall temperatures are fairly reasonable, with a warm bias of 2-4 K (Fig. 10).

The simulated sunlit wall exhibits a double peak in daytime temperature (Figs. 8, 9). The simulated shaded wall, which receives only diffuse radiation, exhibits a smoother relation with time. This behavior accounts for 
Roof

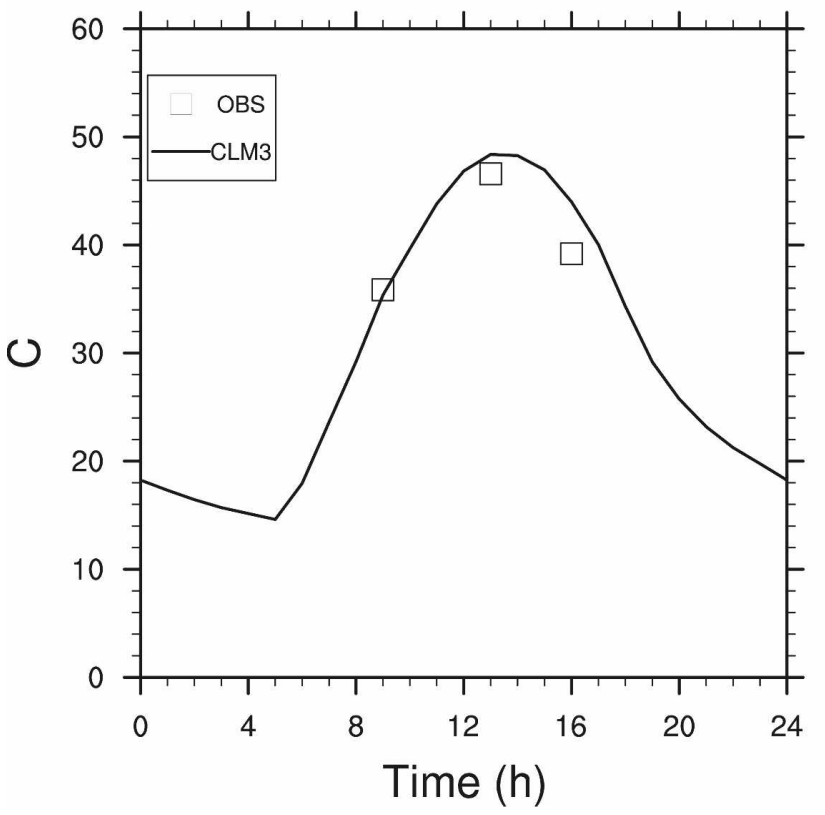

Road

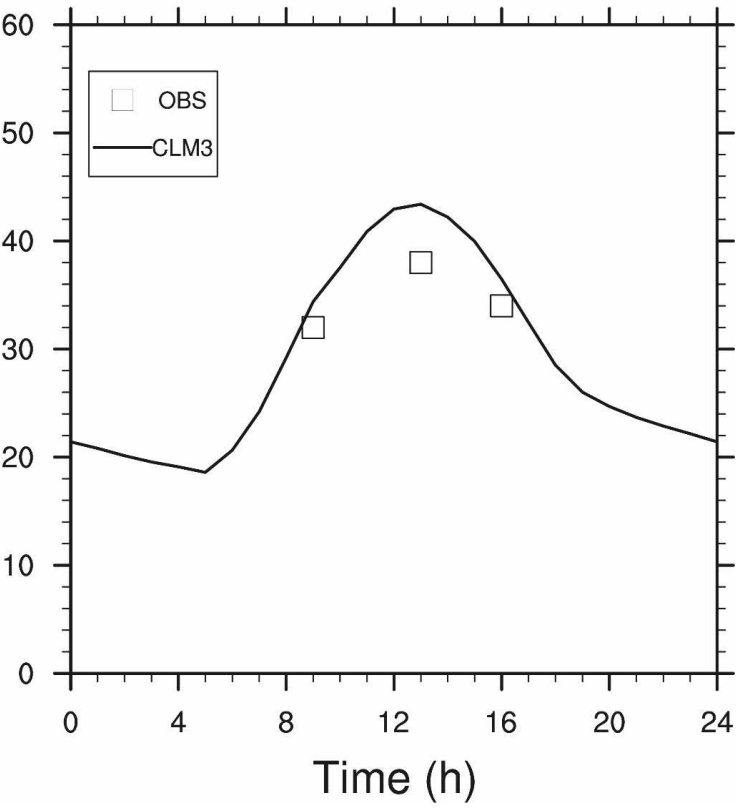

Wall

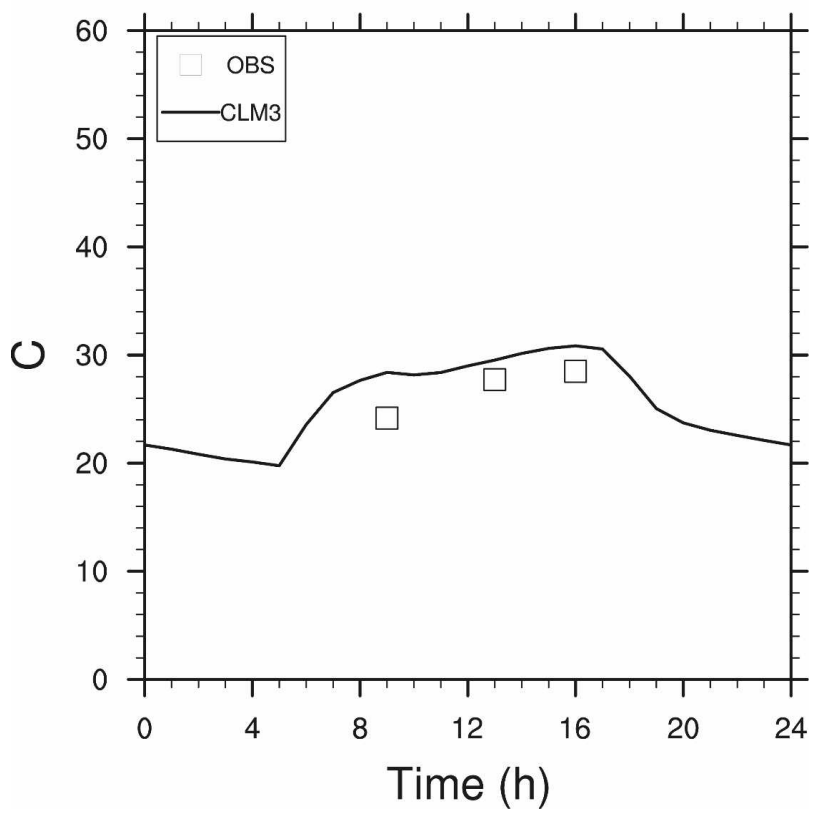

FIG. 10. Diurnal cycle of simulated and observed surface temperatures $\left({ }^{\circ} \mathrm{C}\right)$ for V192 for day 228 (16 Aug). Local-scale observed temperatures are from Voogt and Grimmond (2000).

the early-morning and late-afternoon peaks in average wall temperature seen in observations, and in general the sunlit and shaded walls reasonably account for diurnal variation in wall temperatures. For example, the observed temperature of the north wall remains somewhat constant throughout the day (Fig. 8). The various other walls heat and cool over the course of the day in relation to their particular orientation and the diurnal cycle of solar radiation. The simulated shaded wall fairly well mimics the behavior of the north wall throughout the day, the east wall early in the morning and late in the afternoon, and the south and west walls prior to and following daytime heating by the sun. The temperature of the sunlit wall has an early morning 
peak, is then relatively constant throughout the day, and attains a late-afternoon peak, which closely mimics the temporal behavior of the east, south, and west walls. Note that the incident direct-beam solar radiation for the simulated walls is averaged over all possible canyon orientations, whereas the observed walls are for specific orientations. Period 2 shows similar behavior except that the temperature of the south wall does not increase greatly during the day because of cloudiness (Fig. 9). We emphasize again that although the average simulated wall temperatures are reasonable the sunlit and shaded temperatures would need to be used with caution in applications. For example, the sunlit and shaded walls should not be the same temperature at the end of the sunlit period. Also, the simulated composite sunlit and shaded walls are fixed and are not dynamic as in the real world (Figs. 8 and 9).

With the exception of net radiation, the model does a poorer job of simulating the fluxes at the Vancouver site than at the Mexico City site (Figs. 11, 12). This result is also found for the TEB model. The daytime net radiation is very well simulated for both periods with a bias of less than $3 \mathrm{~W} \mathrm{~m}^{-2}$ and an RMSE of $42 \mathrm{~W} \mathrm{~m}^{-2}$ (Table 5). On the other hand, the nighttime radiative loss is overestimated by $18 \mathrm{~W} \mathrm{~m}^{-2}$ by the model. The release of heat from urban surfaces is too strong in the model, and as a consequence the simulated sensible heat flux is positive at night in contrast with observations. This could be due to higher simulated temperatures in comparison with observations.

Sensible heat flux from the urban surface is overestimated and storage heat flux is underestimated in daytime during both periods, although the simulation is significantly better in the later period. MG02 noted that the poor performance of TEB in period 1 could have been due to the neglect of the advective component of the energy balance, caused by the early-afternoon sea breeze. Indeed, Pigeon et al. (2007) quantified the advective component for a site in Marseilles, France, with a sea breeze and found that probable differences between canyon top and measurement height of up to 100 $\mathrm{W} \mathrm{m}{ }^{-2}$ in sensible heat flux were possible. A similar analysis for the Vancouver site would be required to determine the contribution of the advective component to differences between simulated and observed fluxes. However, a recent reanalysis at this site suggests that the sea-breeze categorization in MG02 may not be appropriate (A. Porson and C. S. B. Grimmond 2008, unpublished manuscript). This is also consistent with the observation that the errors in the model are developed before the early afternoon when the sea breeze would be expected to begin and presumably the errors due to advection become significant. In Part II, our sensitivity studies indicate that there is some sensitivity of the model to the morphological and thermal parameters specified for the site. The parameter values were taken from MG02 and have large uncertainties. Because the model errors in daytime sensible and storage heat flux are of opposite sign (Fig. 11), increasing the thermal admittance (thermal conductivity and heat capacity) of the urban components improves the simulation of both fluxes in daytime but degrades the nighttime fluxes (not shown). Changes to morphological parameters such as increasing $H / W$ and roof and wall thicknesses have similar effects. Neither accounting for the advective term nor an adjustment of the site parameters alone could explain the discrepancy in fluxes, but perhaps some combination of the two could reduce the errors.

In period 2, the sensible heat is consistently overestimated in both daytime (bias of $41 \mathrm{~W} \mathrm{~m}^{-2}$ ) and nighttime (21 $\mathrm{W} \mathrm{m}^{-2}$; Fig. 12, Table 5). The heat storage is simulated well from sunrise through early afternoon; however, heat storage begins to decline about $1 \mathrm{~h}$ later in the observations than in the model, and as a consequence the simulated heat storage turns negative (heat is released from urban surfaces) in the model about $1 \mathrm{~h}$ early. The peak release of heat is much stronger in the model. In both periods, the simulated latent heat flux is less than observed. This is despite the fact that the soil for the pervious fraction was likely initialized as too wet because there was a ban on outdoor water use at the time (Grimmond and Oke 1999b). Best et al. (2006) also found that the MOSES model could not replicate the latent heat flux observed at this site without setting unrealistic conditions.

\section{Summary and conclusions}

The evaluation work presented here for two cities demonstrates that the urban model does a reasonable job of reproducing surface fluxes and temperatures. The overall performance of the model is comparable to that reported by MG02 for the TEB model. The sites tested here constitute two expressions of urban form. The Mexico City site is typical of an urban core with tall buildings and large $H / W$, whereas the Vancouver site is more typical of a light industrial area with smaller $H / W$. Both sites have little pervious fraction. The complexity of the model is such that other urban forms can be accounted for. Outside of the urban/industrial core, the building structure is likely more spatially homogeneous and other measures of urban form, such as pervious fraction, are more heterogeneous. In Part II, we explore the model's sensitivity to variations on urban forms. We examine the sensitivity of the model to the input parameters to quantify the robustness of the 

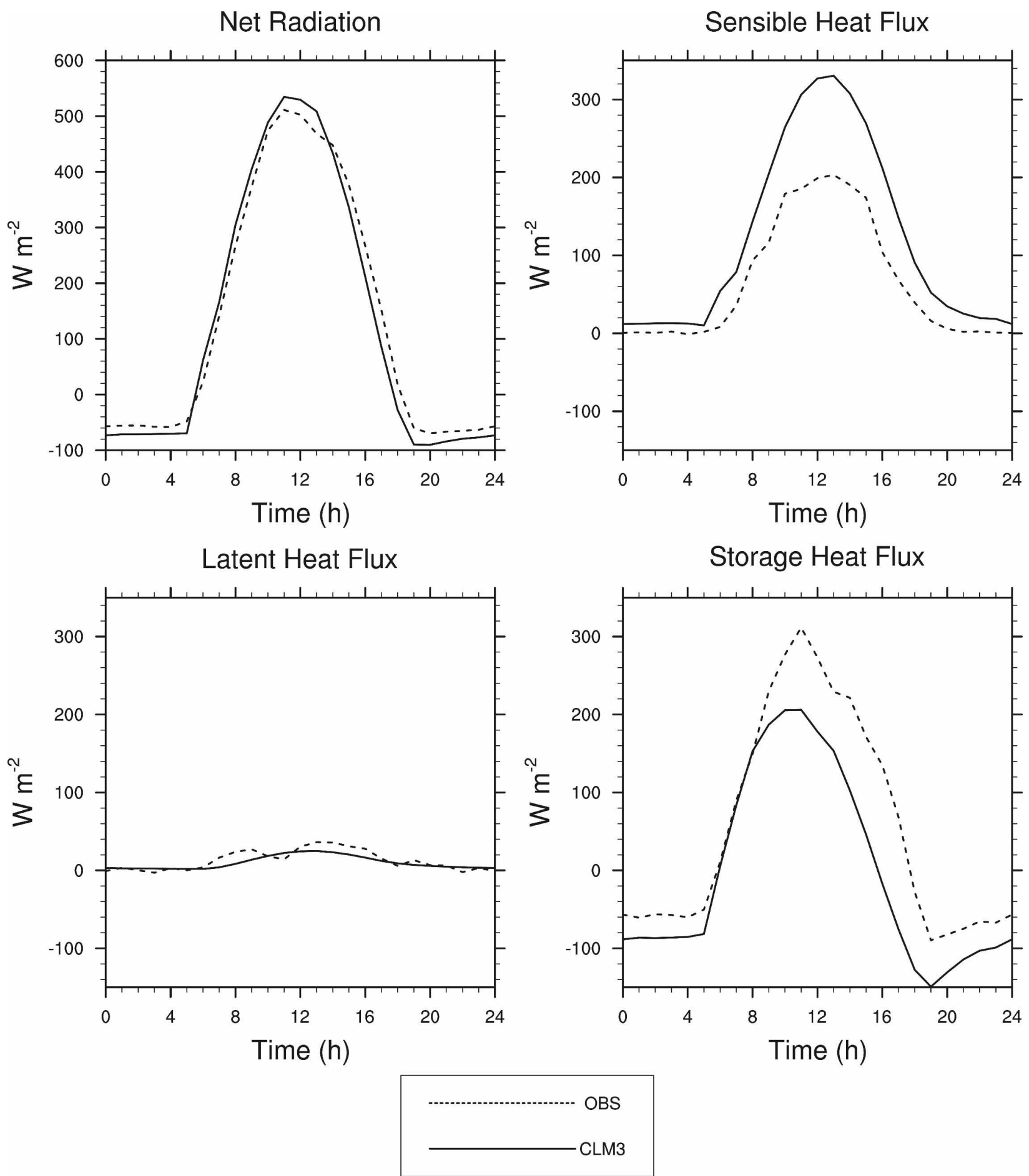

FIG. 11. Average diurnal cycle of simulated and observed heat fluxes for Vl92 for days 225-231 (13-19 Aug 1992).

model and the relative importance of morphological, radiative, and thermal parameters. Such studies inform efforts to develop a global urban database. We also demonstrate the model's ability to simulate observed general characteristics of urban heat islands.
More evaluations are clearly needed. Future work is planned to test and refine the current model for other urban sites (e.g., Grimmond and Oke 2002; Lemonsu et al. 2004). Another potentially useful evaluation tool is an urban model intercomparison exercise such as that 
Net Radiation

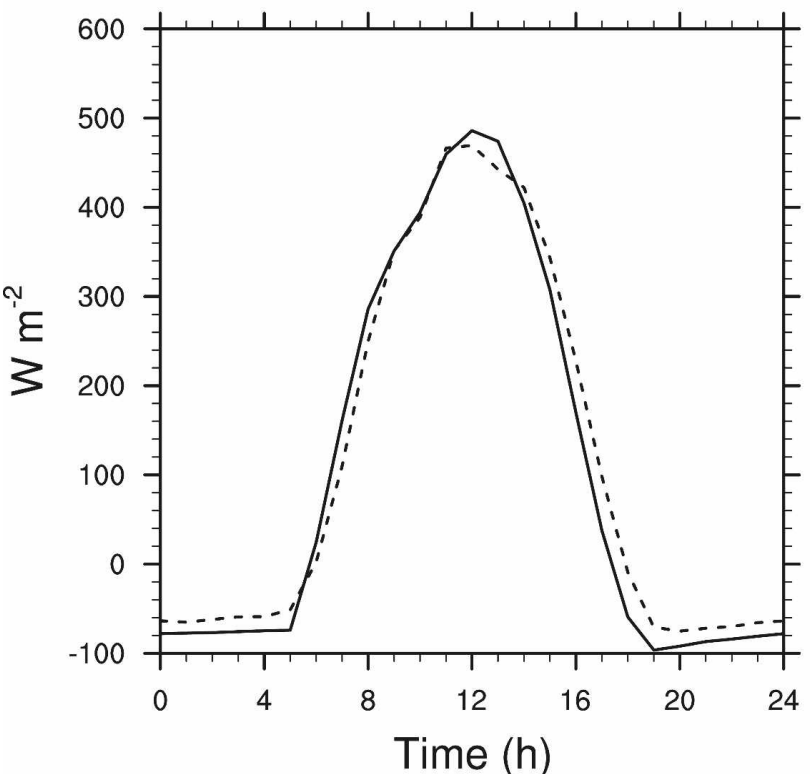

Latent Heat Flux

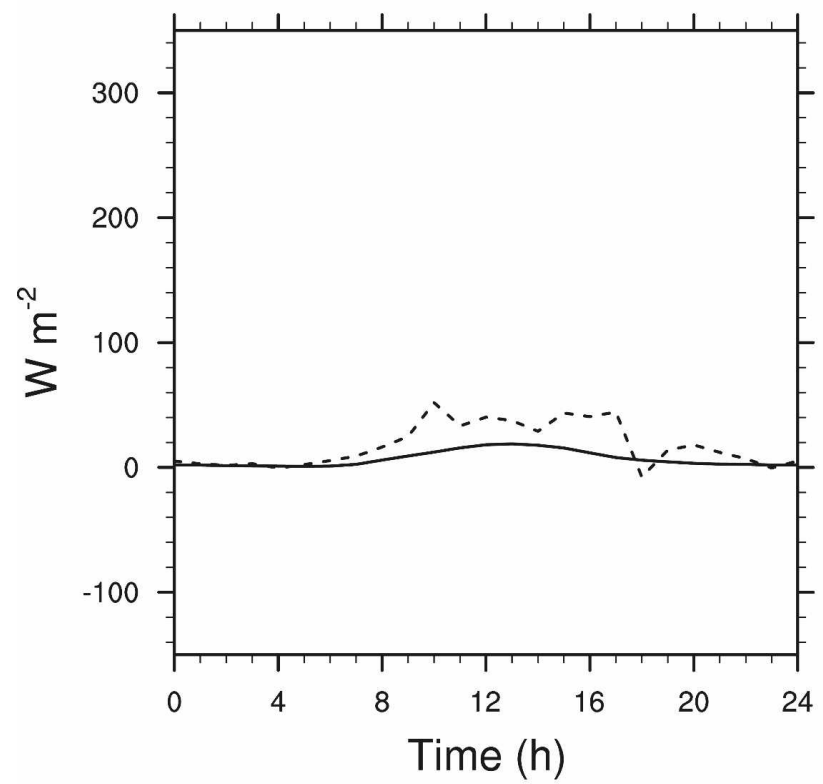

Sensible Heat Flux

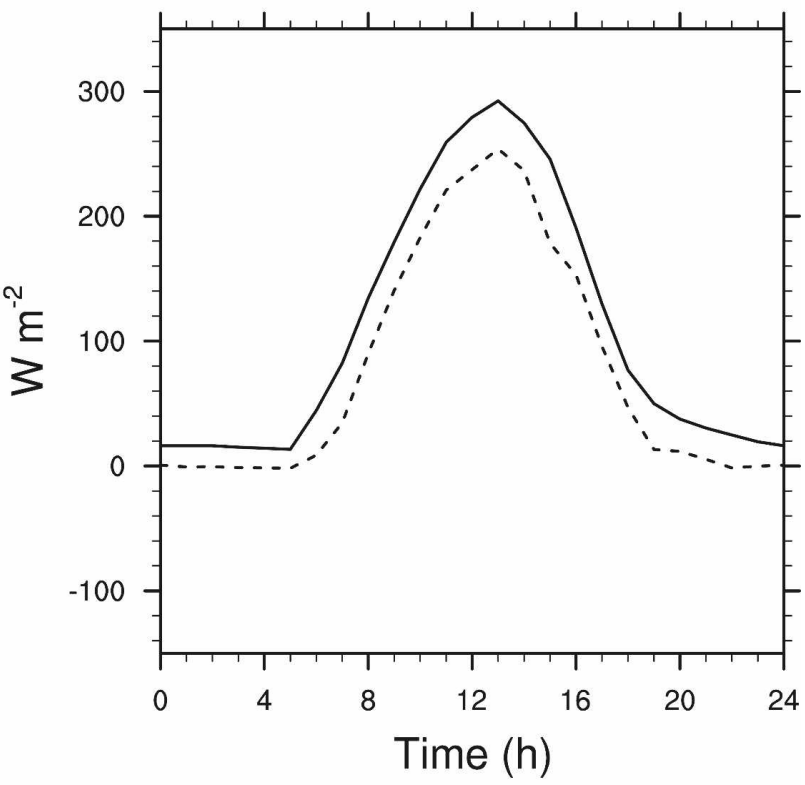

Storage Heat Flux

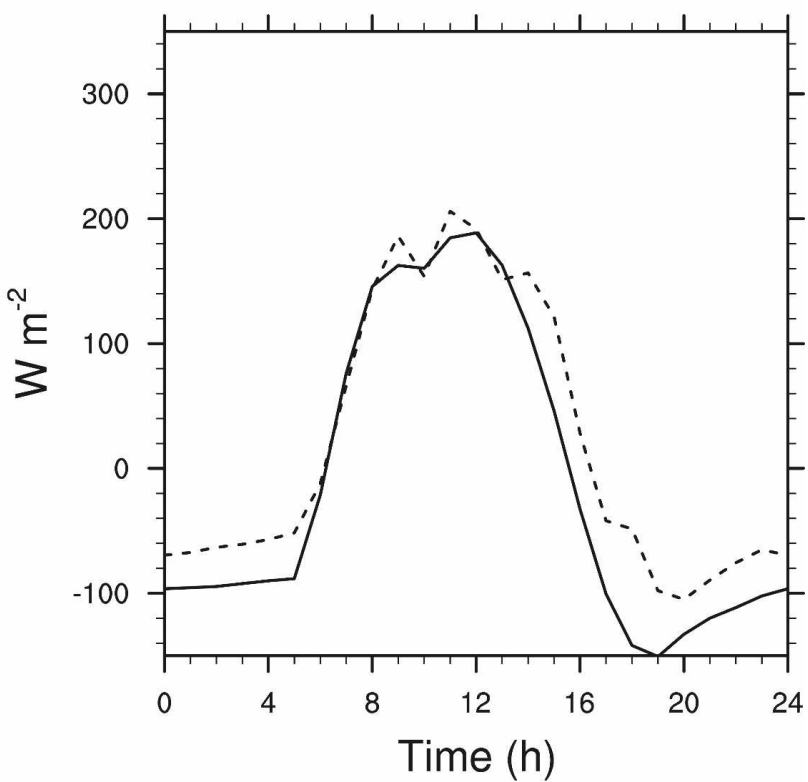

OBS

CLM3

FIG. 12. Average diurnal cycle of simulated and observed heat fluxes for V192 for days 232-236 (20-24 Aug 1992).

suggested by Masson (2006). As Masson (2006) notes, comparable intercomparisons for land surface models emphasizing vegetation schemes have demonstrated the value of such an exercise.

The number of input parameters required to charac- terize an urban area is comparable to the number of input parameters required by the CLM vegetation model. However, the lack of global urban databases is a serious impediment to use of the urban model on a global scale. Urban databases are just now being devel- 
TABLE 5. As in Table 4, but for V192 for two time periods (days 225-231, 13-19 Aug; days 232-236, 20-24 Aug 1992).

\begin{tabular}{|c|c|c|c|c|c|c|c|c|c|}
\hline & \multirow[b]{2}{*}{ Heat flux } & \multicolumn{4}{|c|}{ Days $225-231$} & \multicolumn{4}{|c|}{ Days 232-236 } \\
\hline & & $Q^{*}$ & $Q_{H}$ & $Q_{E}$ & $Q_{S}$ & $Q^{*}$ & $Q_{H}$ & $Q_{E}$ & $Q_{S}$ \\
\hline Overall & Model & 160 & 139 & 11 & 10 & 130 & 121 & 8 & -1 \\
\hline$(N=146:$ days $225-231)$ & Obs & 167 & 77 & 15 & 75 & 140 & 89 & 19 & 29 \\
\hline \multirow[t]{4}{*}{$(N=106:$ days $232-236)$} & Bias & -7 & 62 & -4 & -65 & -10 & 32 & -11 & -30 \\
\hline & RMSE & 34 & 81 & 16 & 86 & 34 & 49 & 23 & 59 \\
\hline & $r^{2}$ & 0.98 & 0.87 & 0.35 & 0.84 & 0.98 & 0.87 & 0.39 & 0.84 \\
\hline & Intercept & -17 & 36 & 7 & -51 & -16 & 35 & 4 & -29 \\
\hline Daytime $\left(Q^{*} \geq 0\right)$ & Model & 322 & 217 & 16 & 88 & 314 & 204 & 12 & 97 \\
\hline$(N=87:$ days $225-231)$ & Obs & 321 & 127 & 23 & 171 & 317 & 163 & 33 & 120 \\
\hline \multirow{4}{*}{$(N=56:$ days $232-236)$} & Bias & 1 & 90 & -7 & -83 & -3 & 41 & -21 & -23 \\
\hline & RMSE & 41 & 102 & 20 & 106 & 42 & 64 & 30 & 71 \\
\hline & $r^{2}$ & 0.95 & 0.72 & 0.14 & 0.65 & 0.93 & 0.69 & 0.16 & 0.58 \\
\hline & Intercept & -25 & 81 & 13 & -48 & -17 & 92 & 9 & 7 \\
\hline Nighttime $\left(Q^{*}<0\right)$ & Model & -78 & 23 & 4 & -105 & -76 & 27 & 3 & -106 \\
\hline$(N=59:$ days $225-231)$ & Obs & -60 & 3 & 3 & -66 & -58 & 6 & 5 & -68 \\
\hline \multirow[t]{4}{*}{$(N=50:$ days $232-236)$} & Bias & -18 & 20 & 1 & -39 & -18 & 21 & -2 & -38 \\
\hline & RMSE & 19 & 23 & 8 & 41 & 22 & 23 & 12 & 42 \\
\hline & $r^{2}$ & 0.50 & 0.48 & 0.15 & 0.68 & 0.71 & 0.74 & 0.02 & 0.55 \\
\hline & Intercept & -40 & 17 & 3 & -20 & -31 & 20 & 3 & -47 \\
\hline
\end{tabular}

oped for individual cities, primarily in the United States, Canada, and Europe (Grimmond and Oke 2002; Grimmond 2006). Methods to aggregate the local-scale parameters that are usually produced by ground-based campaigns to arrive at area-averaged parameters suitable for inclusion in regional and global climate models are still in their infancy. The significant heterogeneity of urban surfaces may require that for modeling purposes urban areas be broken down into finer land units such as city core, industrial/commercial, and residential.

Acknowledgments. Mexico City solar radiation data were provided by Dr. Agustín Mulia Velázquez, Coordinador del Observatorio de Radiación Solar, Instituto de Geofísica, UNAM. This research was supported by the Office of Science (BER), U.S. Department of Energy, Cooperative Agreement DE-FC02-97ER62402, the National Science Foundation Grants ATM-0107404 and ATM-0413540, the National Center for Atmospheric Research Water Cycles Across Scales, Biogeosciences, and Weather and Climate Impacts Assessment Science Initiatives, and the University of Kansas, Center for Research. We thank three anonymous reviewers for comments leading to substantial improvements in the manuscript.

\section{REFERENCES}

Best, M. J., 2006: Progress towards better weather forecasts for city dwellers: From short range to climate change. Theor. Appl. Climatol., 84, 47-55.

_ C. S. B. Grimmond, and M. G. Villani, 2006: Evaluation of the urban tile in MOSES using surface energy balance observations. Bound.-Layer Meteor., 118, 503-525.

Betts, R. A., 2001: Biogeophysical impacts of land use on presentday climate: Near-surface temperature change and radiative forcing. Atmos. Sci. Lett., 2, 39-51.

Bonan, G. B., 1996: A land surface model (LSM version 1.0) for ecological, hydrological, and atmospheric studies: Technical description and user's guide. NCAR Tech. Note NCAR/TN417+STR, 150 pp.

Brown, M., 2000: Urban parameterizations for mesoscale meteorological models. Mesoscale Atmospheric Dispersion, Z. Boybeyi, Ed., WIT Press, 193-255.

Collins, W. D., M. L. Blackmon, G. B. Bonan, J. J. Hack, T. B. Henderson, J. T. Kiehl, W. G. Large, and D. S. McKenna, 2006: The Community Climate System Model version 3 (CCSM3). J. Climate, 19, 2122-2143.

Copeland, J. H., R. A. Pielke, and T. G. F. Kittel, 1996: Potential climatic impacts of vegetation change: A regional modeling study. J. Geophys. Res., 101, 7409-7418.

Cramer, W., and Coauthors, 2001: Global response of terrestrial ecosystem structure and function to $\mathrm{CO}_{2}$ and climate change: Results from six dynamic global vegetation models. Global Change Biol., 7, 357-373.

Dickinson, R. E., K. W. Oleson, G. Bonan, F. Hoffman, P. Thornton, M. Vertenstein, Z.-L. Yang, and X. Zeng, 2006: The Community Land Model and its climate statistics as a component of the Community Climate System Model. J. Climate, 19, 2302-2324.

Eastman, J. L., M. B. Coughenour, and R. A. Pielke Sr., 2001: The regional effects of $\mathrm{CO}_{2}$ and landscape change using a coupled plant and meteorological model. Global Change Biol., 7, 797815.

Elvidge, C. D., and Coauthors, 2004: Urbanization. Land Change Science: Observing, Monitoring, and Understanding Trajectories of Change on the Earth's Surface, G. Gutman et al., Eds., Kluwer, 315-328.

Feddema, J. J., K. W. Oleson, G. B. Bonan, L. O. Mearns, L. E. 
Buja, G. A. Meehl, and W. M. Washington, 2005: The importance of land-cover change in simulating future climates. Science, 310, 1674-1678.

Foley, J. A., and Coauthors, 2005: Global consequences of land use. Science, 309, 570-574.

Grimmond, C. S. B., 2006: Progress in measuring and observing the urban atmosphere. Theor. Appl. Climatol., 84, 3-22.

— areas derived from analysis of surface form. J. Appl. Meteor., 38, 1262-1292.

$\longrightarrow$, and $-1999 \mathrm{~b}$ : Heat storage in urban areas: Local-scale observations and evaluation of a simple model. J. Appl. Meteor., 38, 922-940.

$\longrightarrow$, and -2002 : Turbulent heat fluxes in urban areas: Observations and a local-scale urban meteorological parameterization scheme (LUMPS). J. Appl. Meteor., 41, 792-810.

- H. A. Cleugh, and T. R. Oke, 1991: An objective urban heat storage model and its comparison with other schemes. Atmos. Environ., 25B, 311-326.

Houghton, J. T., Y. Ding, D. J. Griggs, M. Noguer, P. J. van der Linden, X. Dai, K. Maskell, and C. A. Johnson, Eds., 2001: Climate Change 2001: The Scientific Basis. Cambridge University Press, $881 \mathrm{pp}$.

Lemonsu, A., and V. Masson, 2002: Simulation of a summer urban breeze over Paris. Bound.-Layer Meteor., 104, 463-490.

- C. S. B. Grimmond, and V. Masson, 2004: Modeling the surface energy balance of the core of an old Mediterranean city: Marseille. J. Appl. Meteor., 43, 312-327.

Macdonald, R. W., R. F. Griffiths, and D. J. Hall, 1998: An improved method for the estimation of surface roughness of obstacle arrays. Atmos. Environ., 32, 1857-1864.

Martilli, A., A. Clappier, and M. W. Rotach, 2002: An urban surface exchange parameterization for mesoscale models. Bound.-Layer Meteor., 104, 261-304.

Masson, V., 2000: A physically-based scheme for the urban energy budget in atmospheric models. Bound.-Layer Meteor., 94, 357-397.

— 2006: Urban surface modeling and the meso-scale impact of cities. Theor. Appl. Climatol., 84, 35-45.

- C. S. B. Grimmond, and T. R. Oke, 2002: Evaluation of the Town Energy Balance (TEB) scheme with direct measurements from dry districts in two cities. J. Appl. Meteor., 41, 1011-1026.

Offerle, B., C. S. B. Grimmond, and T. R. Oke, 2003: Parameterization of net all-wave radiation for urban areas. J. Appl. Meteor., 42, 1157-1173.

Oke, T. R., 1987: Boundary Layer Climates. 2nd ed. Routledge, $435 \mathrm{pp}$.
— , and H. A. Cleugh, 1987: Urban heat storage derived as energy balance residuals. Bound.-Layer Meteor., 39, 233-245.

— , R. A. Spronken-Smith, E. Jáuregui, and C. S. B. Grimmond, 1999: The energy balance of central Mexico City during the dry season. Atmos. Environ., 33, 3919-3930.

Oleson, K. W., and Coauthors, 2004: Technical description of the Community Land Model (CLM). NCAR Tech. Note NCAR/ TN-461+STR, $173 \mathrm{pp}$

— , G. B. Bonan, J. Feddema, and M. Vertenstein, 2008: An urban parameterization for a global climate model. Part II: Sensitivity to input parameters and the simulated urban heat island in offline simulations. J. Appl. Meteor. Climatol., 47, 1061-1076.

Pielke, R. A., Sr., G. Marland, R. A. Betts, T. N. Chase, J. L. Eastman, J. O. Niles, D. D. S. Niyogi, and S. W. Running, 2002: The influence of land-use change and landscape dynamics on the climate system: Relevance to climate-change policy beyond the radiative effect of greenhouse gases. Philos. Trans. Roy. Soc. London, 360A, 1705-1719.

Pigeon, G., A. Lemonsu, C. S. B. Grimmond, P. Durand, O. Thouron, and V. Masson, 2007: Divergence of turbulent fluxes in the surface layer: Case of a coastal city. Bound.-Layer Meteor., 124, 269-290.

Piringer, M., and Coauthors, 2002: Investigating the surface energy balance in urban areas-recent advances and future needs. Water Air Soil Pollut. Focus, 2, 1-16.

Prata, A. J., 1996: A new long-wave formula for estimating downward clear-sky radiation at the surface. Quart. J. Roy. Meteor. Soc., 122, 1127-1151.

Rowley, F. B., A. B. Algren, and J. L. Blackshaw, 1930: Surface conductances as affected by air velocity, temperature, and character of surface. ASHRAE Trans., 36, 429-446.

Sellers, P. J., and Coauthors, 1997: Modeling the exchanges of energy, water, and carbon between continents and the atmosphere. Science, 275, 502-509.

Shepherd, J. M., 2005: A review of current investigations of urbaninduced rainfall and recommendations for the future. Earth Interactions, 9. [Available online at http://EarthInteractions. org.]

Sparrow, E. M., and R. D. Cess, 1978: Radiation Heat Transfer. Hemisphere, 366 pp.

Taha, H., 1999: Modifying a mesoscale meteorological model to better incorporate urban heat storage: A bulk-parameterization approach. J. Appl. Meteor., 38, 466-473.

Voogt, J. A., and C. S. B. Grimmond, 2000: Modeling surface sensible heat flux using surface radiative temperatures in a simple urban area. J. Appl. Meteor., 39, 1679-1699. 